\title{
RESEARCH
}

Open Access

\section{Spaceborne, UAV and ground-based remote sensing techniques for landslide mapping, monitoring and early warning}

Nicola Casagli ${ }^{1}$, William Frodella ${ }^{1}$, Stefano Morelli ${ }^{1 *}$, Veronica Tofani ${ }^{1}$, Andrea Ciampalini ${ }^{1}$, Emanuele Intrieri ${ }^{1}$, Federico Raspini ${ }^{1}$, Guglielmo Rossi ${ }^{1}$, Luca Tanteri ${ }^{1}$ and Ping Lu ${ }^{2}$

\begin{abstract}
Background: The current availability of advanced remote sensing technologies in the field of landslide analysis allows for rapid and easily updatable data acquisitions, improving the traditional capabilities of detection, mapping and monitoring, as well as optimizing fieldwork and investigating hazardous or inaccessible areas, while granting at the same time the safety of the operators. Among Earth Observation (EO) techniques in the last decades optical Very High Resolution (VHR) and Synthetic Aperture Radar (SAR) imagery represent very effective tools for these implementations, since very high spatial resolution can be obtained by means of optical systems, and by the new generations of sensors designed for interferometric applications. Although these spaceborne platforms have revisiting times of few days they still cannot match the spatial detail or time resolution achievable by means of Unmanned Aerial Vehicles (UAV) Digital Photogrammetry (DP), and ground-based devices, such as Ground-Based Interferometric SAR (GB-InSAR), Terrestrial Laser Scanning (TLS) and InfraRed Thermography (IRT), which in the recent years have undergone a significant increase of usage, thanks to their technological development and data quality improvement, fast measurement and processing times, portability and cost-effectiveness. In this paper the potential of the abovementioned techniques and the effectiveness of their synergic use is explored in the field of landslide analysis by analyzing various case studies, characterized by different slope instability processes, spatial scales and risk management phases.

Results: Spaceborne optical Very High Resolution (VHR) and SAR data were applied at a basin scale for analysing shallow rapid-moving and slow-moving landslides in the emergency management and post- disaster phases, demonstrating their effectiveness for post-disaster damage assessment, landslide detection and rapid mapping, the definition of states of activity and updating of landslide inventory maps. The potential of UAV-DP for very high resolution periodical checks of instability phenomena was explored at a slope-scale in a selected test site; two shallow landslides were detected and characterized, in terms of areal extension, volume and temporal evolution. The combined use of GB-InSAR, TLS and IRT ground based methods, was applied for the surveying, monitoring and characterization of rock slides, unstable cliffs and translational slides. These applications were evaluated in the framework of successful rapid risk scenario evaluation, long term monitoring and emergency management activities. All of the results were validated by means of field surveying activities.

(Continued on next page)
\end{abstract}

\footnotetext{
* Correspondence: stefano.morelli@unifi.it

'Department of Earth Sciences, University of Florence, Via G. La Pira 4, 50121

Florence, Italy

Full list of author information is available at the end of the article
} 
(Continued from previous page)

Conclusion: The attempt of this work is to give a contribution to the current state of the art of advanced spaceborne and ground based techniques applied to landslide studies, with the aim of improving and extending their investigative capacity in the framework of a growing demand for effective Civil Protection procedures in preand post-disaster initiatives. Advantages and limitations of the proposed methods, as well as further fields of applications are evaluated for landslide-prone areas.

Keywords: Landslides, Remote Sensing, SAR data, Optical VHR imagery, GB-InSAR, UAV, Terrestrial Laser Scanning, Infrared Thermography

\section{Background}

Landslides play an important role in the evolution and shaping of aerial/subaerial landscapes (Brunetti et al., 2015), representing a major cause of loss of life, injuries, property damage, socio-economic disruption and environmental degradation (WP/WLI, 1993; Canuti et al., 2004; Petley et al., 2005; Petley, 2012), especially if they are associated with other natural hazards (like earthquakes, volcanic eruptions, meteorological events and wildfires). Because of such habitual combinations, reliable numbers for the social impact only due to landslides are difficult to obtain on a global scale and the economic losses are certainly underestimated (or not quoted at all). This general condition often contributes to reducing the concern individuals and authorities have about landslide risk (Kjekstad, and Highland 2009). Although in most of the disaster-prone areas the consideration of the social-cultural and socio-economic conditions in relation to their physical safety is still very confused, the application of appropriate technologies for landslide detection, monitoring and early warning systems are increasingly considered crucial by local authorities in reducing the risk of landslide disasters. EO from space has found many uses in the natural sciences, but it is only in the last decades that technological advances have also extended to landslides analysis (Mantovani et al., 1996; Ferretti et al., 2001; Canuti et al., 2004; Metternicht et al., 2005; van Westen et al., 2008; Casagli et al., 2010; Martha et al., 2010; Guzzetti et al., 2012; Lu et al., 2012; Tofani et al., 2013a). Nowadays rapid advances are making EO techniques more effective for landslide detection, mapping, monitoring and hazard assessment. Applications are originating from nearly all types of sensors available today (Tofani et al. 2013b). Rapid developments in this field are fostered by the very high spatial resolution obtained by optical systems (currently in the order of tens of centimeters) and by the launching of SAR sensors, purposely built for interferometric applications with revisiting times of few days, such as TerraSAR $\mathrm{X}$ and COSMO-SkyMed (Tofani et al., 2013a). Landslide detection and mapping benefit from both optical (Hervas et al. 2003, Cheng et al., 2004, Marcelino et al., 2009, Martha and Kerle 2012, Lu et al., 2011) and radar imagery (Singhroy, 1995; Fruneau et al., 1996; Massonnet and Feigl, 1998; Kimura and Yamaguchi, 2000; Hilley et al., 2004; Hanssen, 2005; Colesanti and Wasowski, 2006; Meisina et al., 2008; Herrera et al., 2009; 2011; Bardi et al., 2014; Crosetto et al., 2016) to study slow moving landslides. The ability to make numerous point measurements of displacement over the landslide body allows one the detection and mapping of the actively deforming slopes (e.g. Righini et al., 2012), the characterization and monitoring of landslide mechanism (Tofani et al., 2013b) and, through the analysis of time series of deformation, the identification of velocity changes in the landslide evolution (Berti et al., 2013), as well as the modeling of large slope instability (Berardino et al., 2003). Advanced terrestrial remote sensing technologies, such as GB-InSAR, TLS, IRT and digital photogrammetry (DP) are nowadays applied in the field of slope instability detection, mapping and monitoring, for short/long term landslide management (real time, near real time and deferred time) (Lillesand et al., 2014). They are characterized by operational efficiency and accuracy of data not reached by traditional methods: high-resolution acquisition, multifunction versatility, device portability, low cost sensors, easy and fast data processing. Such equipment allows for systematic and easily updatable acquisitions of data that may also enhance the implementation of effective early warning systems at slope scale. In this paper the potential of the abovementioned remote sensing techniques (both spaceborne and ground-based), and their applications for landslide detection and mapping are evaluated.

The presented techniques are described by means of their main technical features and applicability in different observed scenarios, typology of landslide (Cruden and Varnes, 1996; Hungr et al., 2014) and geomorphological setting. Some case studies are also shown and discussed in order to exhibit good practices in landslide characterization and prediction by means of different techniques and sensors in synergic action. The main advantages and disadvantages of the presented techniques are described in the text and in a tabular form. 


\section{Methods: Applied techniques theoretical principles: a state of the art Spaceborne platforms \\ Optical VHR imagery}

The most important active optical satellites are reported in Fig. 1. Optical data are usually used for landslide detection and mapping through visual inspection or analytical methods (Metternicht et al., 2005; Fiorucci et al., 2011; Parker et al. 2014; Guzzetti et al., 2012; Mondini et al., 2014). For example, several optical derivative products (panchromatic, pan sharpen, false colour composits, rationing) can help in visual interpretation for landslide mapping (Casagli et al., 2005; Marcelino et al., 2009; Ma et al. 2016). In image fusion procedures, multispectral channels, characterized by a coarser spatial resolution than the panchromatic, are downscaled through analytical models based on the panchromatic-derived spatial information (Eyers et al., 1998; Chini et al., 2011; Martha and Kerle, 2012; Kurtz et al., 2014). The False Colour Composites (FCCs) of the VHR images are often used to discriminate lithologies or terrain having different characteristics (weathering, water content, vegetation cover) (Ciampalini et al., 2012; Lamri et al., 2016).

The Normalized Difference Vegetation Index (NDVI) derived from optical images, is another index widely used to map landslides by means of evaluating the vegetation cover rate (Lin et al., 2004). Higher values of NDVI can be related to a wide vegetation cover, whereas lower values can represents areas affected by landslides. Furthermore, multispectral images can be enhanced to detect landslides by means of analytical methods based on the spectral characteristics of the land surface and

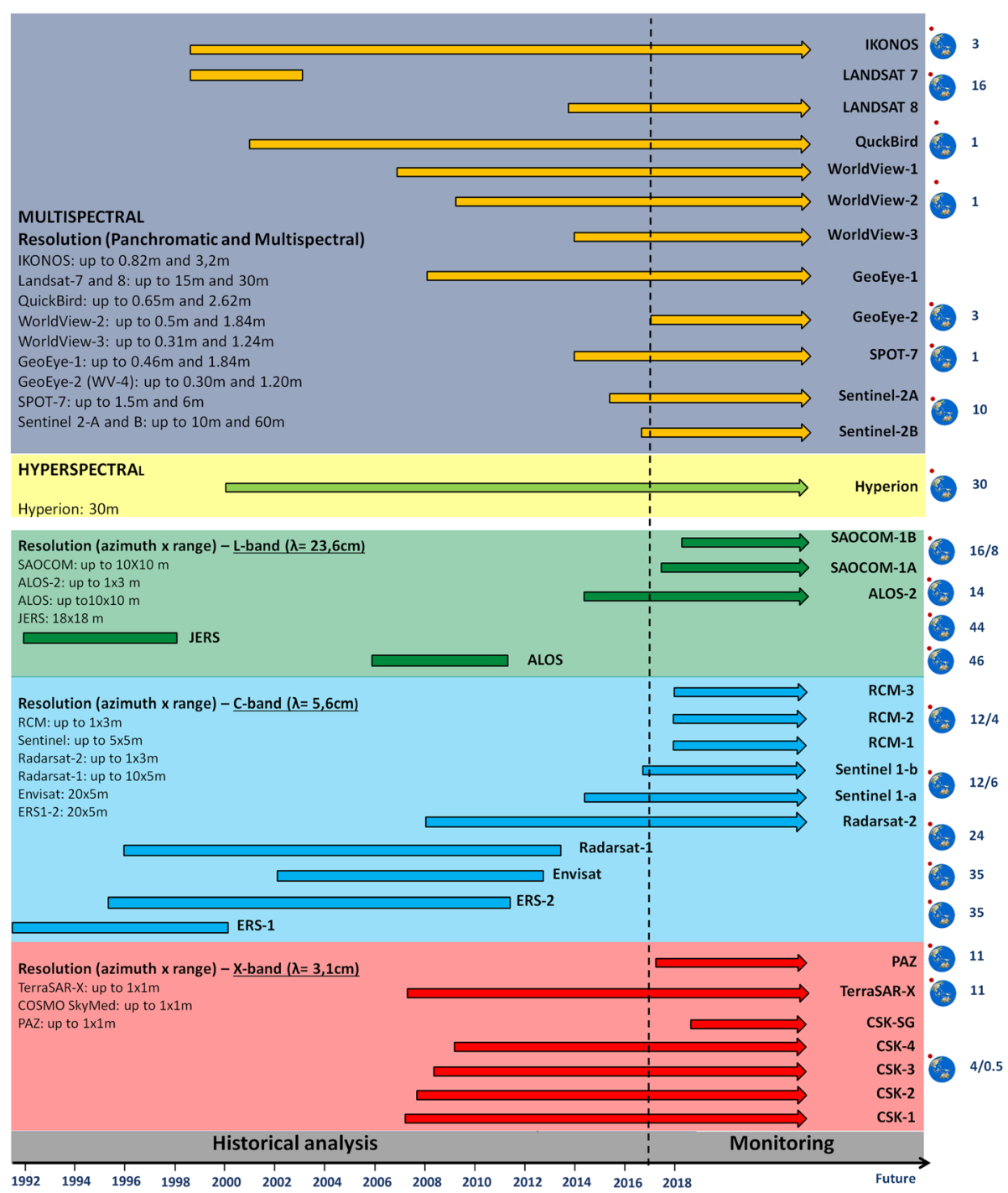

Fig. 1 Active optical and SAR satellites for landslide mapping and monitoring. The numbers on the right of the figure report the revisting time of each satellite. RCM: Radarsat constellation mission, CSK: COSMO-Skymed, CSK-SG: COSMO-Skymed Second Generation 
automatic approaches focus on the classification of image pixels (Martha et al., 2010; Mondini et al., 2011). Few studies have described the use of hyperspectral data for recognition and classification of landslides based on Earth surface characteristics since most of the hyperspectral satellite sensors are still under development (Scaioni et al., 2014).

\section{SAR data}

The family of SAR satellite sensors (Fig. 1) orbits the Earth at an altitude ranging from 500 to $800 \mathrm{~km}$, following sun-synchronous, near-polar orbits, slightly inclined with respect of Earth meridians. The most commonly used bands in SAR applications are C-band $(5-6 \mathrm{GHz}$, $\sim 5,6 \mathrm{~cm}$ wavelength), X-band $(8-12 \mathrm{GHz}, \sim 3,1 \mathrm{~cm}$ wavelength) and L-band (1-2 GHz $\sim 23 \mathrm{~cm}$ wavelength) with a temporal resolution depending on the satellite revisiting time (Fig. 1). A SAR image is composed of pixel characterized by amplitude and phase values. Phase values of a single SAR image is partly depends on the sensor-target distance and is the key element to detect ground displacement. SAR Interferometry is the technique focused on the measure changes of signal phase over time through the analysis of at least two SAR images (Fruneau et al., 1996; Singhroy et al., 1998). A suitable approach to exploit phase variation between two consecutive radar images acquired over the same target is the Differential Interferometric SAR (D-InSAR) (Bamler and Hartl, 1998; Rosen et al., 2000). Geometrical and temporal decorrelation and atmospheric effects caused by the variation of the phase reflectivity value of some radar targets reduce the reliability of the D-InSAR technique (Berardino et al., 2002). In order to overcome these limitations InSAR-based information can be enhanced through multi-temporal interferometric techniques (MIT), based on analysis of long stacks of coregistered SAR imagery (Ferretti et al. 2001; Crosetto et al, 2016). In the past years, several MIT approaches have been developed such as: the Permanent Scatterers Interferometry, named PSInSAR ${ }^{\mathrm{mm}}$ (Ferretti et al., 2011; Colesanti et al., 2003), the SqueeSAR ${ }^{\mathrm{mix}}$ (Ferretti et al., 2011), the Stanford Method for Persistent Scatterers StaMPS (Hooper et al., 2004; Hooper et al., 2007), the Interferometric Point Target Analysis IPTA (Werner et al., 2003; Strozzi et al., 2006), the Coherence Pixel Technique CPT (Mora et al., 2006), the Small Baseline Subset SBAS (Lanari et al., 2004; Berardino et al., 2003), the Stable Point Network SPN (Casu et al., 2006; Crosetto et al., 2008), the Persistent Scatterer Pairs PSP (Herrera et al., 2011) and the Quasi PS technique QPS (Costantini et al., 2008). Signal analysis of a network of coherent radar targets (Permanent Scatterers, PS) allows estimating occurred displacement, acquisitions by acquisition. Line of Sight (LOS) deformation rate can be estimated with an accuracy theoretically better than $0.1 \mathrm{~mm} / \mathrm{yr}$. Each measurement is referred temporally and spatially to a unique reference image and to a stable reference point. MIT analysis is designed to generate time-series of ground deformations for individual PS, assuming different types of deformation models (e.g., linear, nonlinear or hybrid). .In the field of landslide investigations the potential of SAR data has been exploited at different scales: from national (Adam et al., 2011) to regional (Meisina et al., 2008; 2013; Ciampalini et al. 2016a, b) basin (Lu et al., 2012) slope (Frodella et al., 2016) and building scale (Ciampalini et al., 2014; Bianchini et al., 2015; Nolesini et al., 2016), as well as in different phases of landslide response (Canuti et al., 2007) and Civil Protection practice (Farina et al., 2008). Other application fields include subsidence phenomena (Raspini et al., 2012; 2014; Rosi et al. 2014; 2016), earthquakes (Bürgmann et al., 2005; Sousa et al., 2010) and volcanic activities (Hooper et al., 2004; Vilardo et al., 2010; Parker et al., 2014).

\section{UAV and Ground-based methods $U A V-D P$}

$\mathrm{DP}$ is a well-established technique for acquiring dense 3D geometric information in slopes from stereoscopic overlaps of photo sequences captured by a calibrated digital camera (Chandler, 1999; Lane et al., 2000; Sturzenegger and Stead, 2009; Zhang et al., 2004). During past few years, with the rapid development of DP techniques and the availability of ease-using, focusable and relatively cheap digital cameras, this technique gained wide applications in many fields, such as 3D building reconstruction, heritage protection and landslides studies (Grussenmeyer et al., 2008; Scaioni et al., 2015; Fan et al., 2016). In this latter field, depending on the camera lens-setting, DP can be divided into two fields of activity (Gopi, 2007): far range, usually more exploited for landslide characterization and general mapping (Wolter et al., 2014), and close range, having a wide use in high precision metrological and deformation monitoring applications (Cardenal et al., 2008; Scaioni et al., 2015). More recently the combination of rapid development of low cost and small UAVs and the improvements of conventional sensors in terms of cost and size, led to new, promising scenarios in environmental remote sensing, surface modelling and monitoring (Colomina and Molina, 2014; James and Robson, 2012; Remondino et al., 2011; Eisenbeiss and Sauerbier, 2011).

\section{GB-InSAR}

GB-InSAR system consists of a computer-controlled microwave transceiver, characterized by a transmitting and receiving antennas, which by moving along a mechanical linear rail is capable to synthesize a linear aperture 
along the azimuth direction (Tarchi et al., 1997; Rudolf et al., 1999; Pieraccini et al., 2002). The obtained SAR image contains amplitude and phase information of the observed scenario backscattered echo in the acquiring time interval (from few to less than 1 min with the most modern systems) (Luzi et al., 2004; 2010; Monserrat et al., 2014). In a GB-InSAR interferogram the displacement obtained from the phase difference calculation can be represented in 2D maps, in which the chromatic scale covers a total value corresponding to half of the wavelength used. However, since the phase is periodic, it cyclically assumes the same values crating imageinterpreting problems. This issue, known as phase ambiguity, and can be solved through interpretation based on field geological knowledge or by adopting apposite phase unwrapping algorithms (Ghiglia \& Romero, 1994), which count the number of cycles performed by the wave obtaining cumulated displacement maps. Given the relative short distances at which GB-InSAR apparatuses usually operate (typically less than $3 \mathrm{~km}$ ), they work in $\mathrm{Ku}$ band $(1.67-2.5 \mathrm{~cm})$. The main research applications of GB-InSAR soon became focused on slope monitoring (Tarchi et al., 2003; Pieraccini et al., 2002; 2003), for civil protection purposes (Del Ventisette et al., 2011; Intrieri et al., 2012; Bardi et al., 2014; 2016; Lombardi et al., 2016) and, more recently, for mining safety (Farina et al., 2011; Severin et al., 2014). Other fields include volcanoes monitoring (Di Traglia et al., 2013; 2014a; 2014b; Intrieri et al., 2013; Nolesini et al., 2013; Calvari et al., 2016), cultural heritage sites (Tapete et al., 2013; Pratesi et al., 2015; Nolesini et al., 2016; Frodella et al., 2016), glaciers and snowpack sinkholes (Intrieri et al., 2015).

\section{TLS}

A TLS device produces and emits a beam characterized by a directional, coherent and in-phase electromagnetic radiation (Jaboyedoff et al., 2012). The laser scanner by measuring with high accuracy (millimeter or centimeter) the back-scattered laser signal, is capable of obtaining the exact position of a mesh of points (point cloud), characterized by $(\mathrm{x}, \mathrm{y}, \mathrm{z})$ cartesian coordinates (Slob et al., 2002; Frohlich and Mettenleiter, 2004; Turner et al., 2006; Slob et al., 2007). The device high acquisition rate (up to hundreds of thousands points per second) makes the detailed 3D shape of the object available in a short operating time. By defining the coordinates of specific laser reflectors within the surveyed area through a Differential Global Positioning System in Real Time Kinematic mode (DGPS-RTK; Morelli et al., 2012; Tapete et al., 2015; Pazzi et al., 2016), it is possible to link the obtained high-resolution 3D surface digital model to a global reference system. In landslide studies TLS has been increasingly used for the geometrical and geostructural characterization and unstable rock cliffs monitoring applications (Abellán et al. 2006; 2011; Jaboyedoff et al., 2007; Ferrero et al., 2009; Oppikofer et al. 2009; Gigli et al. 2014a, b, c). Thanks to the high resolution of the laser scanning survey it is also possible to extract even the smallest features, such as the structural crack pattern, the crack opening direction (Gigli et al., 2009; 2012), and the orientation of critical discontinuities within the rock mass (Gigli and Casagli, 2011; Gigli et al., 2014b). Furthermore, this technique is capable of measuring ground $3 \mathrm{D}$ temporal displacements by comparing sequential datasets of the same scenario (Rosser et al., 2005; Abellán et al., 2011). The intensity data can also provide some information about the type of material and the soil moisture content of the targets, which can add information regarding the landslide main geomorphologic features (Voegtle et al., 2008; Franceschi et al., 2009).

\section{IRT}

IRT is the branch of remote sensing dealing with measuring the radiant temperature of Earth's surface features from a distance (Spampinato et al. 2011). The product of an infrared thermographic survey is a pixel matrix (thermogram), collected through the thermal camera array detector (Maldague, 2001), which following the correction of the sensitive parameters (object emissivity, path length, air temperature and humidity) represents a radiant temperature map of the investigated object. The presence within the observed surface of fractures, subsurface voids, moisture and seepage zones, will influence the material thermal characteristics (density, thermal capacity and conductivity) modifying its heat transfer (Teza et al., 2012). Therefore, the presence of an inhomogeneity within the observed scenario will be displayed in the corresponding radiant temperature map as an irregular thermal pattern with respect to the surroundings (a "thermal anomaly") (Frodella et al., 2014b). In recent years IRT has undergone a significant increase of applications in the field of geosciences (Spampinato et al. 2011), nevertheless in the study of slope instability processes it is still experimentally used, except for a few interesting experimental studies (Wu et al., 2005; Baroň et al. 2012; Frodella et al., 2014b). In particular, IRT (often coupled with laser scanning) is applied with the following purposes: i) obtain information about the rock mass fracturing (Squarzoni et al. 2008); ii) detect shallow surface weakness in rock walls (Teza et al. 2012); iii) perform rockfall/slide susceptibility assessment (Gigli et al. 2014a, c; Teza et al. 2015); iv) map ephemeral drainage patterns (Frodella et al., 2014a; 2015); v) integrate traditional geo-structural and geomechanical surveys (Mineo et al., 2015; Mineo and Pappalardo 2016; Pappalardo et al., 2016).

\section{Results: Study area applications}

In this section, the potential of the presented techniques and their synergic use is explored for the detection, 
mapping, and monitoring of landslides, through various case studies characterized by different types and scales of instability phenomena, hazardous scenarios and operational modes (Fig. 2). The employed remote sensing systems are listed in Table 1.

\section{Spaceborne platforms}

The study areas for spaceborne applications comprise two different mountain chain sectors (the Peloritani and the Nebrodi mountains; Sicily Island, Southern Italy; Fig. 2), in which the geological features are characterized by the typical features of recently uplifted areas, developed on a crystalline basement with steep slopes and shallow clayey soil cover. In the late afternoon of October $1^{\text {st }} 2009$, an intense storm affected the area between the Peloritani Mountains ridge and the Ionian coastline (Ciampalini et al., 2015a; Del Ventisette et al., 2012), where the main villages are located. During the same night, the persisting rainfall triggered more than 600 landslides, such as shallow soil slides and debris flows, on an area of about $50 \mathrm{~km}^{2}$. The assessed number of fatalities caused by landslides and inundation was 37 (including 31 deaths and 6 missing persons), with 122 injured people and 2019 evacuated people (Ardizzone et al., 2012; Del Ventisette et al., 2012; Raspini et al., 2013); the worst damages were reported in the village of Giampilieri (Fig. 2). Furthermore, between 2009 and 2010, following heavy and persisting heavy rainfall, several municipalities in the Nebrodi Mountains were strongly affected by several complex, rotational and deep-seated landslides which damaged buildings and infrastructures
(Ciampalini et al., 2014; Bardi et al., 2014; Bianchini et al., 2015; Ciampalini et al. 2015a, b; 2016a,b).

\section{Object-Oriented Analysis (OOA) for mapping shallow rapid-moving landslides: the Giampilieri case study}

The purpose of this case study is to introduce a new approach for a rapid mapping of newly-triggered landslides using an objected-oriented change detection technique. The methodology aims at a semi-automatic and rapid analysis with a minimum of operator involvement and manual analysis steps. Compared to conventional approaches for landslide mapping, this approach benefits from (i) an image segmentation with problem-specified scale optimization, and (ii) a multi-temporal analysis at object level with several systemized spectral and textural metrics. This procedure has been applied to the two of the most damaged areas of Giampilieri, including a training area $\left(\right.$ ca. $1.8 \mathrm{~km}^{2}$ ) for algorithm development, and a larger independent testing area $\left(\mathrm{ca} .8 .1 \mathrm{~km}^{2}\right)$. The latter allows the robustness and transferability of the algorithm (without any change of ruleset and threshold) and the corresponding accuracy to be assessed by comparison with a manually mapped landslide inventory prepared from fieldworks and subsequent modifications from image interpretation. Two Quickbird images acquired on September $6^{\text {th }} 2006$ and October $8^{\text {th }} 2009$, with $0.3 \%$ and zero cloud cover respectively, were used in the study (Table 1). The application with the optical data is based upon the OOA (Lu et al., 2011). OOA is mainly dealing with the measuring unit of 'object', which can be defined as individually resolvable entities located within a digital image which are perceptually generated
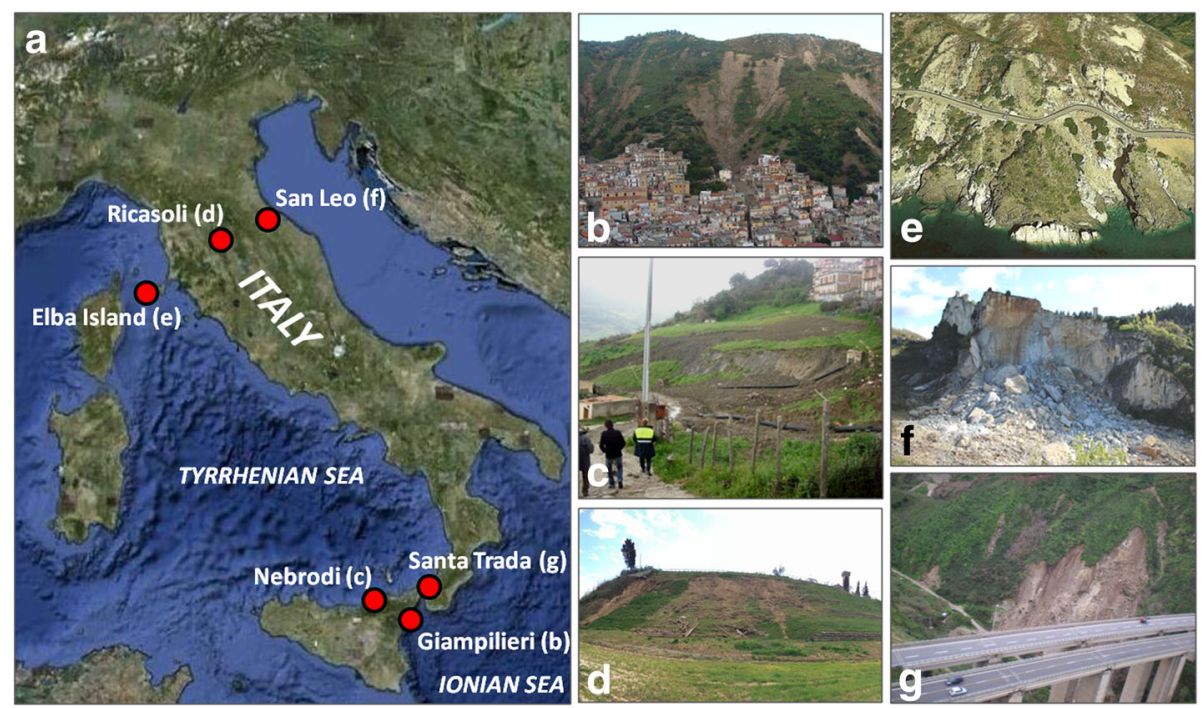

Fig. 2 a Landslide case studies location; b Giampilieri (debris flows); c Nebrodi area (complex landslides); d Ricasoli (shallow landslides); e Western Elba Island (unstable rock masses); f San Leo (collapsed rock cliff); g Santa Trada (translational slide) 
Table 1 Technical features of the described remote sensing systems

\begin{tabular}{|c|c|c|c|c|c|c|}
\hline System type & Optical VHR & SAR & GB-INSAR & TLS & UAV-DP & IRT \\
\hline Satellite/Device Model & Quickbird & Envisat/Ers/Radarsat1/CSK & Ellegi-LiSALab & Riegl LMS-Z420i & $\begin{array}{l}\text { Canon } \\
\text { Ixus 240hs }\end{array}$ & FLIR SC620 \\
\hline Wavelenght & $\begin{array}{l}\text { VIS/N-IR } \\
0.4-0.9 \mu \mathrm{m}\end{array}$ & $\begin{array}{l}\text { C-band }(5.6 \mathrm{~cm}) \\
\text { X-band }(3.1 \mathrm{~cm})\end{array}$ & Ku band $(\approx 1.7 \mathrm{~cm})$ & $\mathrm{N}-\mathrm{IR}(0.74-1.4 \mu \mathrm{m})$ & $\begin{array}{l}\text { VIS } \\
(0.39 / 0.74 \mu \mathrm{m})\end{array}$ & $\begin{array}{l}\text { LW-IR } \\
(7.5-13 \mu)\end{array}$ \\
\hline $\begin{array}{l}\text { Revisiting time/ } \\
\text { Measurement rate }\end{array}$ & $1-3.5$ days & $\begin{array}{l}35 / 24 \text { (days) } \\
12 \text { hours (at } 40^{\circ} \text { latitude) }\end{array}$ & $\approx 1 / 4 \mathrm{~min}$ & $12000 \mathrm{pt} / \mathrm{s}$ & 24 frame/s & 30frame/s \\
\hline Image spatial/resolution & $2.4 \mathrm{~m}$ & $\begin{array}{l}20 \times 5 / 10 \times 5 / \\
1 \times 1(\mathrm{~m})\end{array}$ & $\begin{array}{l}0.3 \times 0.75 \mathrm{~cm} \\
\text { (at } 100 \mathrm{~m} \text { distance) }\end{array}$ & $0.008^{\circ}$ & $4608 \times 3456$ pix & $640 \times 480$ pix \\
\hline Maximum distance/Range & $450-482 \mathrm{~km}$ & $\begin{array}{l}\text { 772-774/782-785/ } \\
793 / 620(\mathrm{~km})\end{array}$ & $3-4 \mathrm{~km}$ & $800 \mathrm{~m}$ & $150 \mathrm{~m}$ & $-40 / 500^{\circ} \mathrm{C}$ \\
\hline $\begin{array}{l}\text { N-E-ellipsoidic height/ } \\
\text { Accuracy }\end{array}$ & 23 m (horizontal) & $\begin{array}{l}\text { 2-6-1.5 m(C-Band) } \\
1-4-1.5 \text { m (X band) }\end{array}$ & $<1 \mathrm{~mm}$ & $\pm 10 \mathrm{~mm}$ & $1-5 \mathrm{~cm}$ & $\pm 2^{\circ} \mathrm{C}$ \\
\hline
\end{tabular}

from high-resolution pixel groups' (Hay et al., 2003). Detailed information on the methodology and the algorithm developed can be found in Lu et al. (2011). The algorithm developed based on the training area was directly applied in the testing area.

The final outputs for the testing area are shown in Fig. 3: in order to evaluate the accuracy of this approach, OOA-derived landslides were compared with a manuallymapped landslide inventory. The accuracy assessment was carried out for the number and the spatial extent of mapped landslides. For the spatial extent of landslides a user's accuracy of $75.9 \%$ and a producer's accuracy of $69.9 \%$ were achieved. In terms of the number of landslides, user's and producer's accuracies of 81.8 and $69.5 \%$, respectively, were reached.

\section{Detection and mapping of slow-moving landslides with SAR data: the Sicily case studies}

Spaceborne SAR analysis of ground deformation in the Peloritani (nearby the Giampilieri village) and Nebrodi area (Fig. 2) was performed using the SqueeSAR approach (Ferretti et al., 2011). The SqueeSAR algorithm has been applied to C-band SAR dataset acquired by ERS (08/09/1992 - 24/11/2000) and Envisat (22/01/ 2003-20/05/2009) missions along ascending orbits. Following the approaches proposed by Farina et al. (2008) and Bianchini et al. (2012), deformation measurements extracted by means of SqueeSAR technique have been coupled and integrated with thematic maps (topographic and geological maps), optical data (ortophoto, optical satellite VHR images and multi-temporal aerial photos) and available landslides inventory maps, in order to identify the areas characterized by high hydro-geological hazard (hotspot mapping), related to the occurrence of extremely and very slow moving landslide (according to the classification of Cruden \& Varnes, 1996). Twenty-six sites have been identified, for which landslides have been detected and mapped (Fig. 4). On the basis of available multi-interferometric data these sites were assessed as the most critical in terms of hydro-geological hazard, both for the type of instability detected and/or the extent of the mapped phenomena and/or the measured
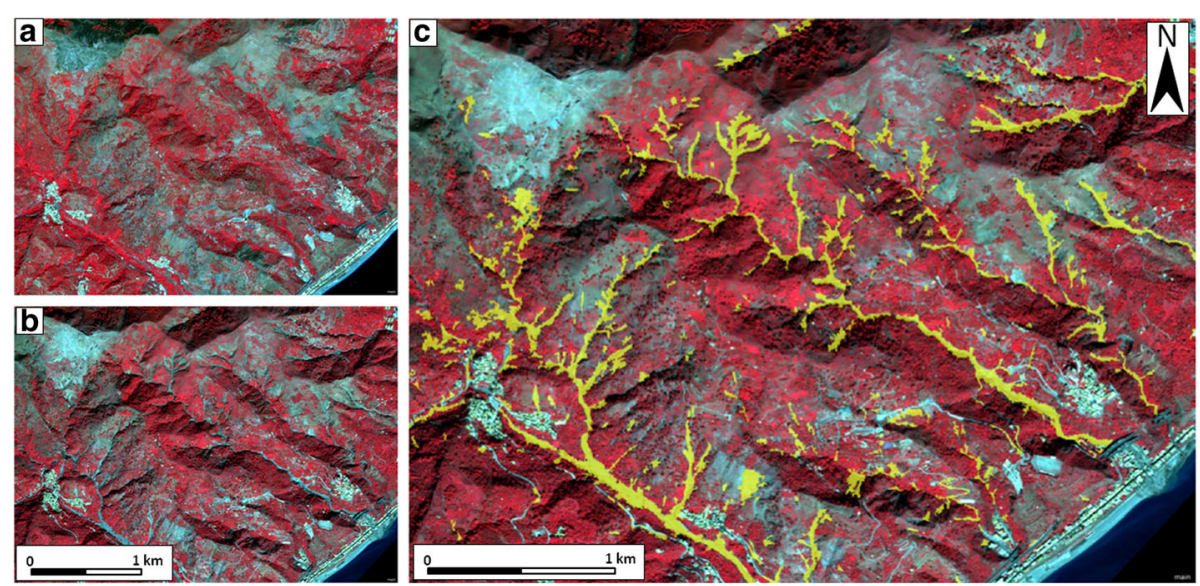

Fig. 3 The used Quickbird imagery in the optical VHR analysis of Giampilieri area (Peloritani mountains): a pre-event QuickBird imagery; b post-event QuickBird imagery (false color 4-3-2); c The result of OOA landslide mapping in the independent testing area (yellow areas = mapped shallow landslides) 


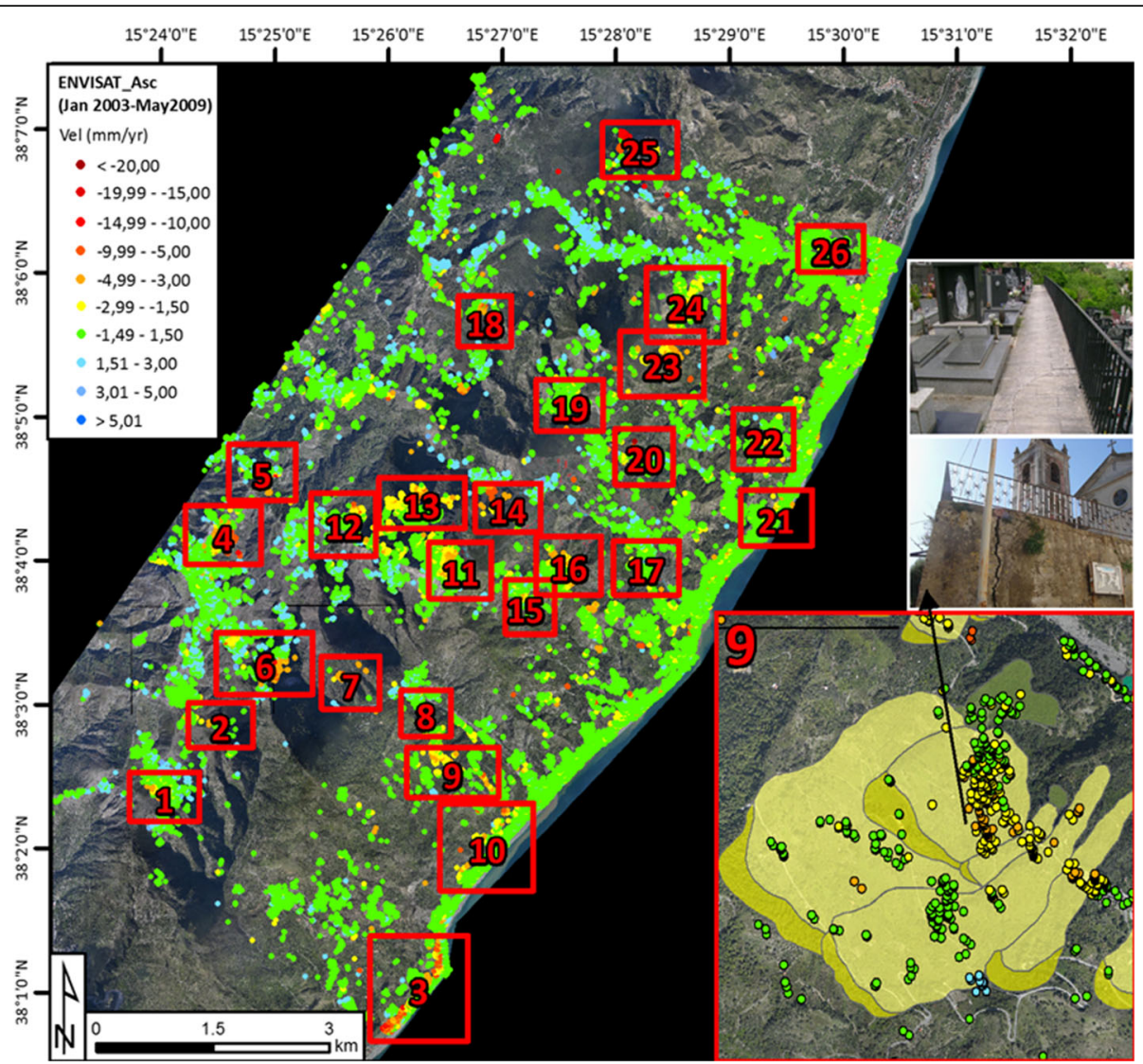

Fig. 4 Location of the twenty-six sites in the Nebrodi area which are characterized by high hydro-geological risk (hotspot mapping) according to the D-InSAR analysis. In the inset the landslide mapping of the village of Croce is reported

deformation velocities and/or the presence of elements at risk. In the inset of Fig. 4 the hotspot analysis for the area of the village of Croce (identified with number 9) is reported. The area is located on the right bank of the Guidomandri creek and is characterized by the presence of several elements at risk, including, beside the village itself, isolated buildings and minor settlements. Preexisting landslide inventory maps do not report slope instability in the study area.

The SqueeSAR results also show a large sector of the slope characterized by a displacement with velocity ranging from 1.6 to $4.8 \mathrm{~mm} / \mathrm{yr}$ Envisat dataset (2003-2009). Photo-interpretation of stereoscopic colour images (1:3500 scale) and analysis of information provided by SqueeSAR results allow to detect and map a large complex system of active continuous slides affecting the area. Such deformation rates do not pose threat to population, but can cause, persisting for many years, damages to buildings and manmade infrastructures. Cracks and damages have been surveyed during field validation, which also helped to confirm the presence and the extension of the active movements through the identification of tension cracks, scarps and counterscarps.
After the 2009 and 2010 events that affected the Nebrodi Mountains, the SqueeSAR technique was applied to characterize the triggered hillslope phenomena both at the basin and at the local scale (Fig. 5). At the basin scale, SqueeSAR PSI data was applied to update the available Landslide Inventory Map (LIM) including information on typology and state of activity of each identified landslide. The updating procedure has been performed using: (i) radar interpretation of four different available SAR datasets; (ii) photo-interpretation of 1:33000 scale aerial photographs flown in 1954, 1955 and 2005; and (iii) field surveys. InSAR displacement measurements were acquired in different periods (2006-2009, RADARSAT-1 scenes and 2011-2012, COSMO-SkyMed images). Considering the limitation of the adopted technique, the updating of the pre-existing LIM was limited to the extremely slow and very slow moving landslides (faster phenomena have been excluded due to their rapid kinematics).

The new LIM (Fig. 5) includes 566 events: 15 (2.7\%) rockfalls and topples, 136 (24.0\%) complex landslides, 188 (33.2\%) flows and 227 (40.1\%) slides, covering an area of $74.1 \mathrm{~km}^{2}$. The comparison between the preexisting and the new LIMs has been performed using 


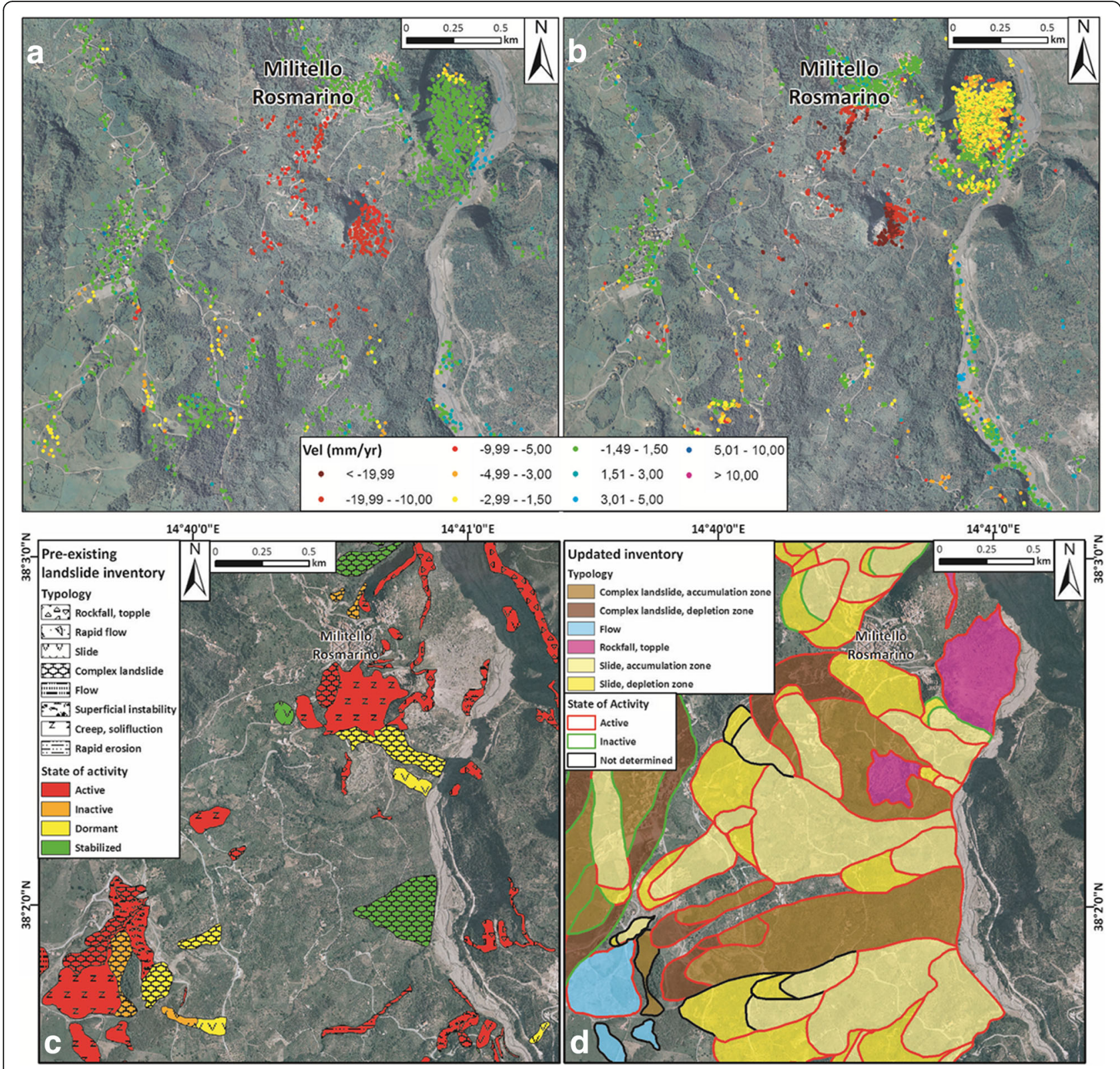

Fig. 5 Ground deformation velocity maps in the surroundings of Militello Rosmarino town (Nebrodi) obtained using Radarsat-1 (a) and COSMOSkyMed (b) PSI data. Pre-existing LIM (c) and updated LIM (d)

three classes: (i) confirmed, (ii) enlarged with respect to the pre-existing LIM and (iii) new (landslide not included in the pre-existing LIM). This approach led to the enlargement of 120 events (21.2\%) of the preexisting LIM, to the confirmation of 155 events (27.4\%), and to the recognition of 291 (51.4\%) new phenomena.

\section{UAV and Ground based methods}

\section{UAV-DP for landslide characterization and mapping: The} Ricasoli case study

A periodical check was performed in the Ricasoli village (Upper Arno river Valley,Tuscany, Italy; Fig. 2), in order to evaluate the potential of UAV-DP to characterize and to monitor landslides. In particular, a multitemporal photogrammetric survey, carried out for the northern slope of Ricasoli, are compared to define at very high resolution, morphologic features of the slope and their evolution in time. The survey was performed using a multicopter drone (Saturn) with an innovative perimetric chassis, fully designed, built and patented by the Department of Earth Science of the University of Florence (Fig. 6). The images were processed using Agisoft Photoscan Professional (Agisoft LLC, 2016) software and the resulting data were implemented in a GIS environment using the ESRI ArcGIS 


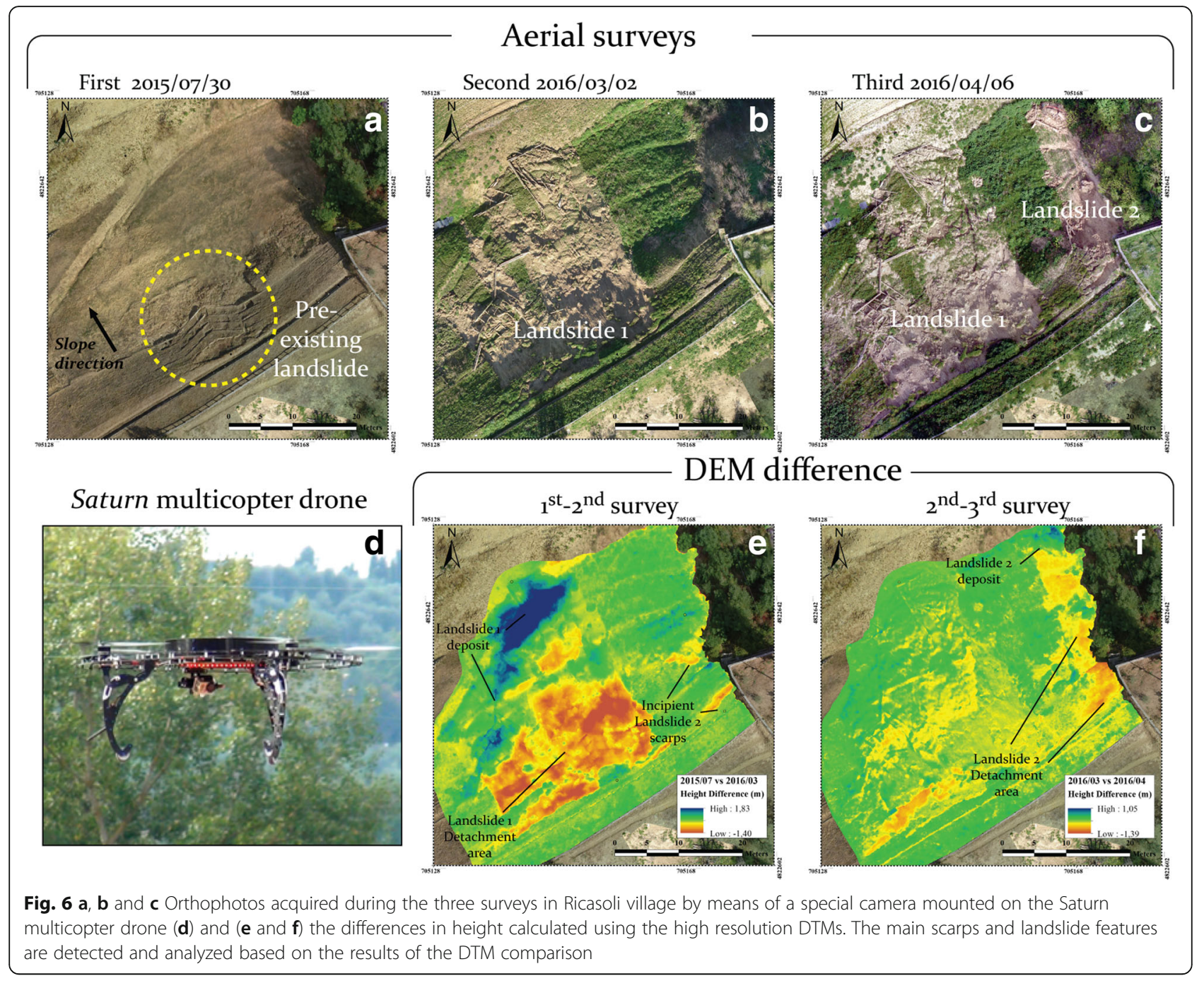

package. Three 3D point clouds, acquired at a few months one to each other and filtered in order to remove all the points processed on trees and high vegetation, were used to build high-resolution DTMs (0.05 m/pix) (Fig. 6). The DTMs were compared to detect any morphological change between the three acquisitions, to characterize the landslides and, in addition, to precisely point out features as indicators of landslide-prone areas on the slope (Fig. 6). As a result, two landslides were detected and characterized, in terms of areal extension, volume and temporal evolution. The overall extent and volume of the mass movements detected in Ricasoli are summarized in Table 2. The slope is currently being monitored by performing repeated aerial surveys, and the assessed landslide evolution is being used as an input for current mitigation works planning.

\section{TLS and IRT for risk scenario assessment: the Elba Island case study}

The investigated area is located on the western Elba Island coastline (Central Italy), along a $250 \mathrm{~m}$ stretch of a local panoramic roadway (provincial roadway $\mathrm{n}^{\circ} 25$ ) (Fig. 2). The area is characterized by very steep rock slopes overlooking the roadway, which due to their complex geostructural setting and degree of fracturing (Gigli et al., 2014a), in 2009 underwent the detachment of rock mass portions and rock debris. In order to define the risk scenarios for the roadway transportation security conditions, the slope instability occurrences were investigated through a methodology based on the integration of accurate geological and geomechanical field surveys and terrestrial remote sensing techniques, such as TLS and IRT (Frodella and Morelli, 2013; Gigli et al., 2014a). IRT surveys in particular were carried out in

Table 2 Extent and volume of the landslides occurred in the northern slope of Ricasoli during the period of study

\begin{tabular}{llll}
\hline Landslide & Occurrence & Extent $\left(\mathrm{m}^{2}\right)$ & $\begin{array}{l}\text { Extimate } \\
\text { Volume }\left(\mathrm{m}^{3}\right)\end{array}$ \\
\hline Landslide1 & $01 / 03 / 2016$ & 950 & 480 \\
Landslide2 & $09 / 03 / 2016$ & 320 & 70 \\
\hline
\end{tabular}


correspondence of rock mass most critical sectors, in order to detect thermal anomalies connected to open fractures, water seepage and moisture zones, validate the unstable block volume calculation, and rapidly assess the hydraulic conditions along the more critical rock mass discontinuities. The obtained TLS 3D surface model contributed to characterize the morphological variability of the investigated area: a rough morphology, characterized by creek erosion gullies isolating jutting rock mass portions (Fig. 7c). Figure 6c shows the stereographic projection of the collected field survey structural data: five main discontinuity sets were identified, JN3 set in particular, including high persistent decimetric-spaced discontinuity planes (=exfoliation joints, EJ) dipping parallel with respect to the slope, represent slipping planes isolating large rock mass portions.

Furthermore a semi-automatic geo-structural survey was performed by means of a Matlab tool (DiAna = Discontinuity Analysis; Gigli and Casagli 2011), on a limited sector of the rock mass not covered by nets, rock bolts, and fences. Figure $7 \mathrm{~d}$ reports the poles of the semiautomatically extracted discontinuities (labeled from D1 to D7, and represented in 3D in Fig. 7b). Given the geological setting of the investigated area, and the most probable detected failure mechanism occurring (planar failure along JN3 discontinuity set), an iterative procedure was applied with the aim of identifying the maximum credible scenario. A Matlab routine was built for this purpose by moving on the 3D surface a plane with the same orientation of JN3 set. By selecting a volume threshold value of $1000 \mathrm{~m}^{3}$, three protruding rock masses were detected and labeled from north to south as M1, M2, and M3 (Figs. 7a and 8a, b, c).

M3 rock mass, in addition to the basal slipping plane, is also delimited southeastward from the stable portion of the rock slope by a second sub-vertical plane (belonging to JN2 set in Fig. 5c and D3 in Fig. 5d). The obtained surface temperature maps highlighted warm thermal anomalies connected to air circulation were detected in correspondence of the open portions of the JN3 discontinuities delimiting the detected M1, M2, and M3 masses (Fig. 8g, h, i). The abovementioned discontinuities detected on the thermograms follow closely the EJ basal planes; this interpretation was strengthened by the comparison of the thermograms with the optical images that confirmed no evidence of water flow along the detected discontinuities. For these reasons, dry conditions were diagnosed for all M1, M2, and M3 basal slipping planes, and the absence of water pressure was considered in the carried out stability analysis (Gigli et al., 2014a). The resulting assessed rock mass volumes (expressed in cubic meter) are 3706 (M1), 4359 (M2), and 1293 (M3) respectively (Fig. 8c, d, e).

\section{Long-term monitoring of collapse-affected rock wall by means of GB-InSAR, TLS and IRT: The San Leo case study}

The town of San Leo is located in the southwestern sector of the Emilia Romagna Region (northern Italy; Fig. 2), on top of a limestone isolated rock massif overlying clayey slopes, which is historically affected by instability

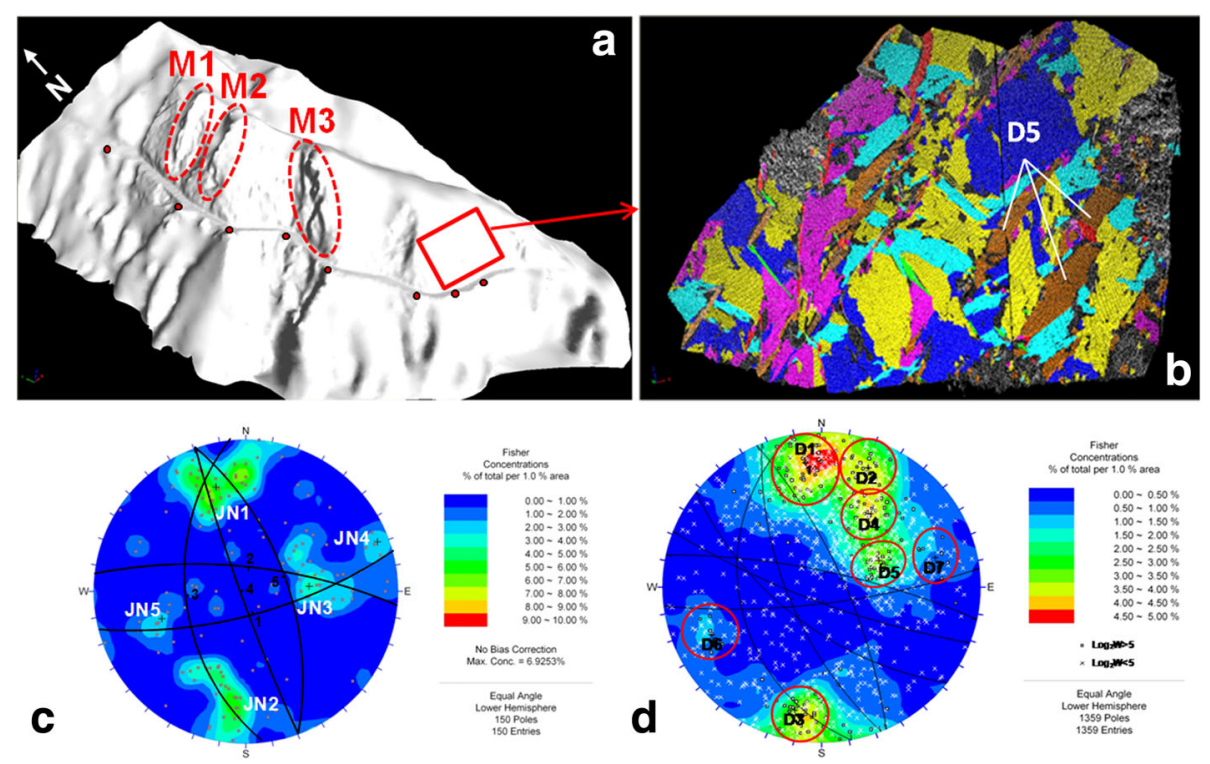

Fig. 7 a High-definition 3D surface of the western Elba coastline (dots mark the different TLS scan positions, the square delimitates semiautomatic geomechanical surveyed area; $\mathbf{b}$ 3D representation of all the joint sets extracted; stereographic projection of discontinuity poles and modal planes of the main sets collected in the investigated area by means of traditional field surveys (c), and the semi-automatic analysis (d) (modified after Gigli et al., 2014a) 


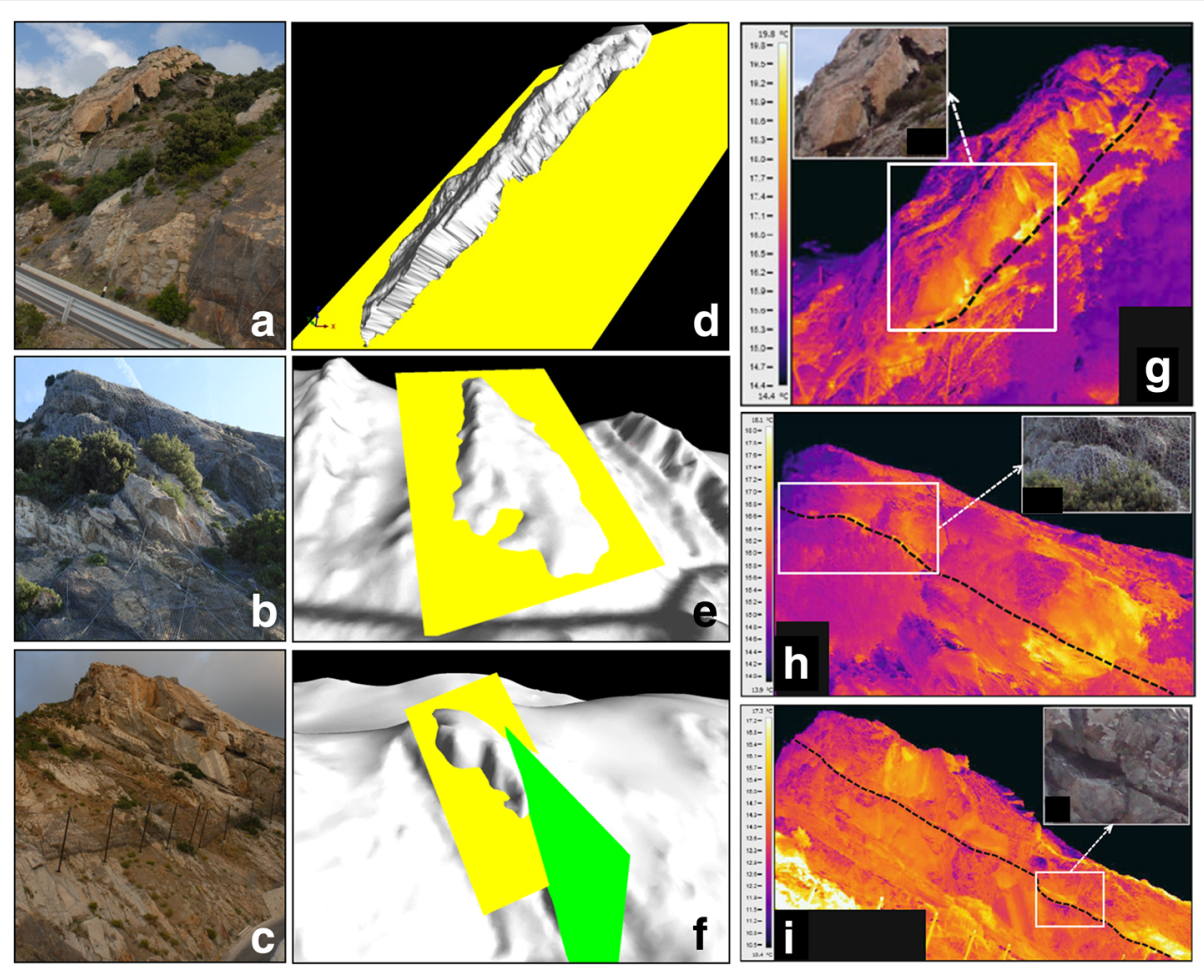

Fig. 8 Optical images of the unstable rock masses of the western Elba coastline $(\mathbf{a}=M 1 ; \mathbf{c}=M 2 ; \mathbf{e}=M 3)$; related 3D digital model with the detected basal and lateral slipping planes (b, d, f); mosaicked thermograms from IRT ( $\mathbf{g}=\mathrm{M1}$, $\mathbf{h}=\mathrm{M} 2$, and $\mathbf{i}=\mathrm{M} 3$ ) acquired around 1 p.m., November 2011 (dotted lines mark the basal slipping planes; white squares on the thermogram allow a comparison with the correspondent sectors in the optical images, acquired by the builtin digital camera) (modified after Gigli et al., 2014a)

phenomena. On February $27^{\text {th }}, 2014$ an entire portion of the rock plate north-eastern sector collapsed, causing a huge rockfall. Following the event a GB-InSAR monitoring activity coupled with TLS surveys was carried out, in order to manage the post-event emergency phase and evaluate the residual risk (Frodella et al., 2016). Furthermore, IRT surveys were performed in order to integrate the TLS and GB-InSAR data for the rock wall characterization. The obtained 3D terrain model revealed a rock wall surface, characterized by criticalities such as overhanging sectors, ledges and niches (Fig. 9a). $3 \mathrm{D}$ temporal variations of the terrain model were detected by comparing sequential datasets acquired in the carried out different laser scanning surveys; the resulting 3D rock wall temporal variations, from March $7^{\text {th }} 2014$ to December $18^{\text {th }} 2014$ (Fig. 9b, c). The deformational field analysis provided evidence of an ongoing rock block toppling (with an estimated volume of $450 \mathrm{~m}^{3}$ ), which displacement evolution reached values ranging from 12 to about $50 \mathrm{~cm}$ (Fig. 9b, c). The scan comparison also provided the detection of minor rockfall phenomena (areas colored in blue in Fig. 9b, c) which volumes are listed in Table 3.

The TLS 3D model was merged with the GB-InSAR data obtaining a 3D GB-InSAR cumulative displacement map, which allowed to read detected LOS displacements directly on the observed scenario 3D representation, and therefore both to better localize the most critical areas, and compare the different techniques displacement data (Fig. 10).

The GB-InSAR data acquired during the first monitoring year allowed to assess a general stability of the rock cliff and the observed town structures, and to detect critical areas, corresponding to: i) a detensioned rock block located at the foot of the monitored rock wall central sector (confirming the TLS analysis of an ongoing rock block toppling); and ii) the rockfall deposits (metric and decametric size boulders and blocks in a coarse sandy-clayey matrix, corresponding to the maximum recorded cumulative displacement in the investigated area. Surface temperature maps collected on April $9^{\text {th }} 2014$ (following a period characterized by local intense rainfall) allowed to detect widespread seepage sectors in correspondence of a rock mass key discontinuity, corresponding to a high persistent normal fault dissecting the whole rock massif (oval 1 in Fig. 10b, c). In this geological, morphological and structural context discontinuities affected by seepage represent potential criticalities with respect to instability phenomena, as confirmed by minor seepage sectors (ovals 4 in Fig. 9b, c), which are 


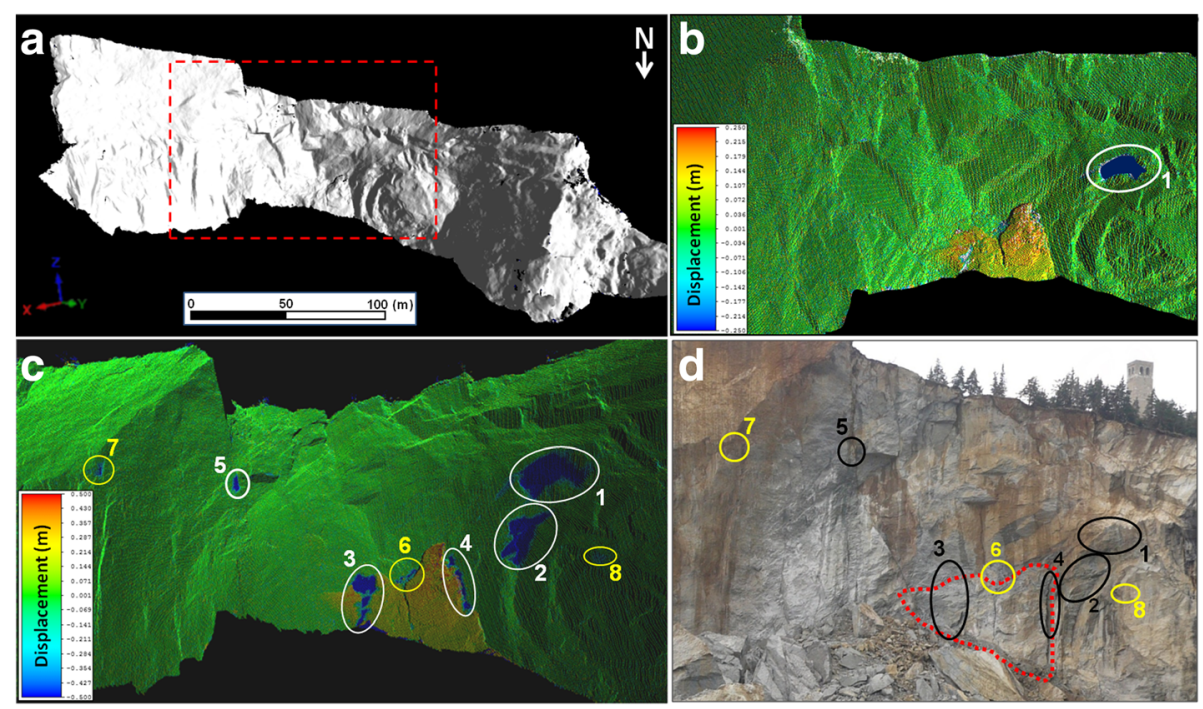

Fig. 9 a High-resolution 3D surface of the surveyed rock wall in Sal Leo rock cliff (red dashed square corresponds to the area affected by block detachments). b Comparison between March $7^{\text {th }}$ 2014-April 9th 2014 TLS scans: white oval showing the first monitored rock block detachment; orange-yellow areas enhance rock wall sector characterized by displacements. c Comparison between March $7^{\text {th }}$ 2014-December 18th 2014 scans, enhancing the occurred detached rock block sectors (in blue); yellow ovals enhance the minor block detachments. $\mathbf{d}$ Correspondent sectors in optical image (black ovals enhance major detachments; dashed line delimits the rock wall displaced sector); (after Frodella et al., 2016)

located in correspondence of rock wall sectors affected by a widespread fracture network and block detachments (ovals 1-2 in Fig. 10c, d).

\section{Short-term GB-InSAR monitoring for emergency management: Santa Trada case study}

The Santa Trada landslide (Calabria Region, Southern Italy; Fig. 2) occurred on January $30^{\text {th }} 2009$, after a period characterized by heavy rainfall (Del Ventisette et al., 2011), putting at high risk a viaduct sector along the A3 national motorway, and could have also dammed the stream below. It is a $100 \mathrm{~m}$ high, $90 \mathrm{~m}$ wide translational slide (estimated thickness is between 3 and $5 \mathrm{~m}$ ), developed in sand and conglomerates originating from metamorphic weathered rocks (Fig. 11). For safety reasons this tract of the motorway was closed to traffic and on $31^{\text {st }}$ January a ground-based had been installed. Already

Table 3 Detected detached rock blocks and calculated volumes (after Frodella et al., 2016)

\begin{tabular}{lll}
\hline Detached sector & Calculated volume $\left(\mathrm{m}^{3}\right)$ & Time interval (2014) \\
\hline 1 & 94 & April 9th - June 11th \\
2 & 66 & June 11th - December 18th \\
3 & 44 & \\
4 & 15 & \\
5 & 10 & \\
6 & 2 & \\
7 & 1.5 & \\
8 & 1 & \\
\hline
\end{tabular}

on February $2^{\text {nd }} 2010$, after a short-monitoring campaign the motorway was partially reopened, thanks to the structure stability assessment performed by means of the first GB-InSAR monitoring data (Figs. 11 and 12). During the mid-term monitoring campaign (lasted until April $24^{\text {th }} 2010$ ) two approaches for calculating the interferograms and displacement maps were adopted:

- Differential: the time span between the first and last image composing the interferogram is kept constant (e.g. 1 day) and the interferograms represent sequential moments (e.g. day-by-day displacement). This approach is used in particular for kinematic analyses as it permits to identify acceleration phases because it enables to evaluate two comparable time periods.

- Incremental: the first image is taken as a reference and the interferograms are all calculated between the reference and the last image; in this way the time span is increasing with time. This approach is useful to evaluate the total cumulative displacement and to measure the displacement even in the slower portions of the landslide. Furthermore, it is suitable for spatial analyses as the total extension of the unstable area can be assessed. On the other hand, long time intervals can cause phase ambiguity and loss of coherence.

For the Santa Trada landslide, thanks to the displacement maps provided by the GB-InSAR system, it was possible to delimitate the area affected by the movement (Fig. 11) and to identify some temporal phases characterized by different 

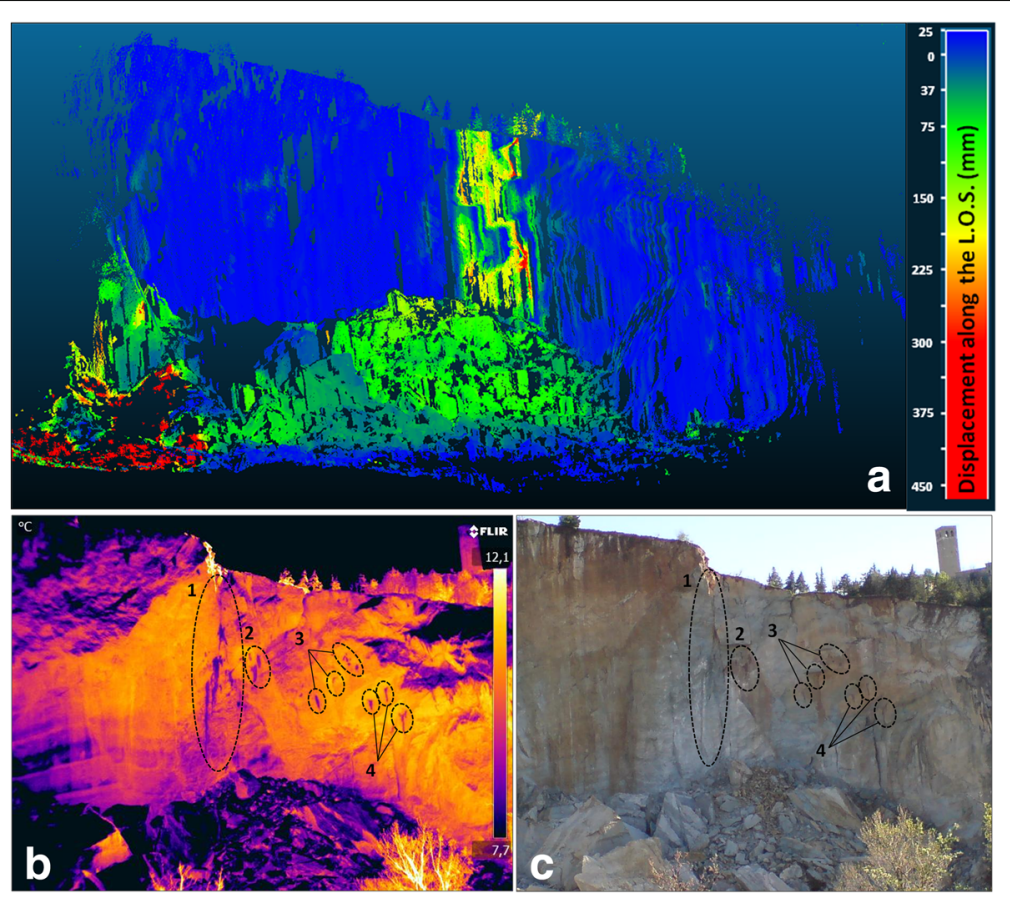

Fig. 10 GBInSAR and TLS data integration. a San Leo rock wall March 7th 2014 - 2015 3D GB-InSAR cumulative displacement map (after Frodella et al., 2016). b Thermogram acquired during April $9^{\text {th }} 2014$ (after Barla et al., 2016); c correspondent photo (seepage sectors 1-4 are characterized by lower temperatures, due to local rock wall surface cooling caused by water evaporation)

activity levels and to assess the risk scenarios temporal evolution (Fig. 12).

\section{Discussion}

The reliability and effectiveness of the described remote sensing techniques, as well as their synergic use, have been enhanced, providing a wide range of surveying and monitoring activities for different landslide types (Fig. 13).

A brief overview of applications (individual or combined technique) has been shown through some selected case studies in section 3 . In this section the abovementioned case studies are discussed in order to show, for the employed techniques their main advantages and

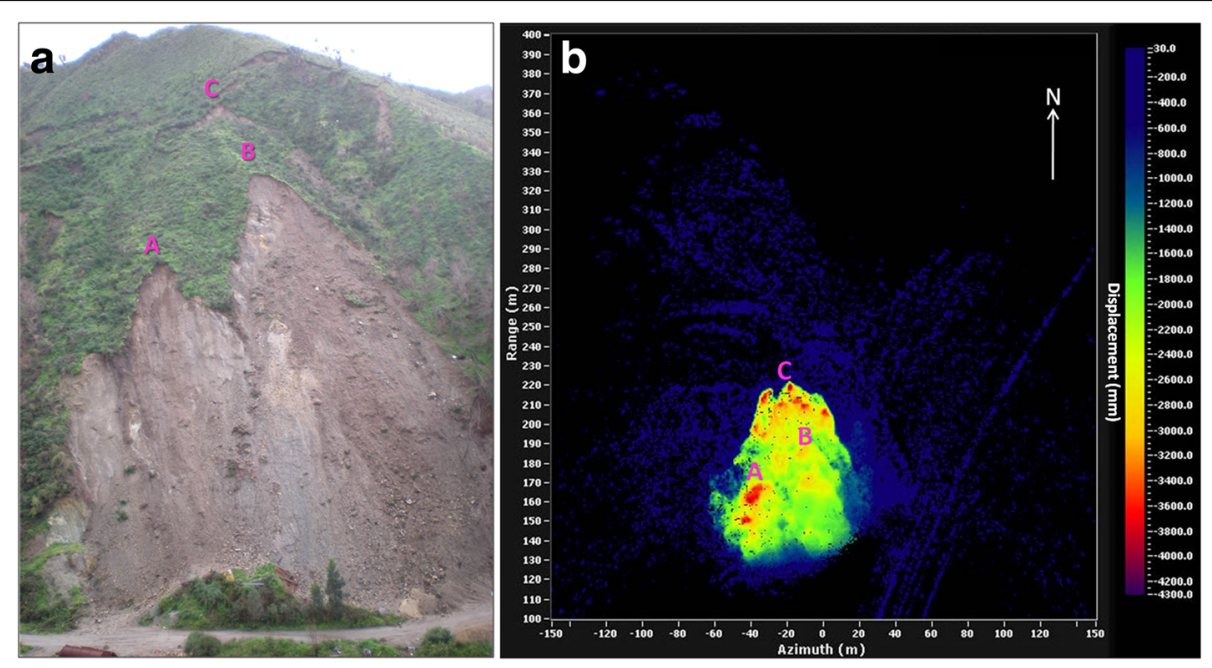

Fig. 11 a Photo of the Santa Trada landslide, $1^{\text {st }}$ February 2009; b cumulated displacement map calculated using GB-InSAR data with incremental approach spanning from 2nd February to 29th April 2009. The letters indicate the corresponding points between the two images (after Del Ventisette et al., 2011) 


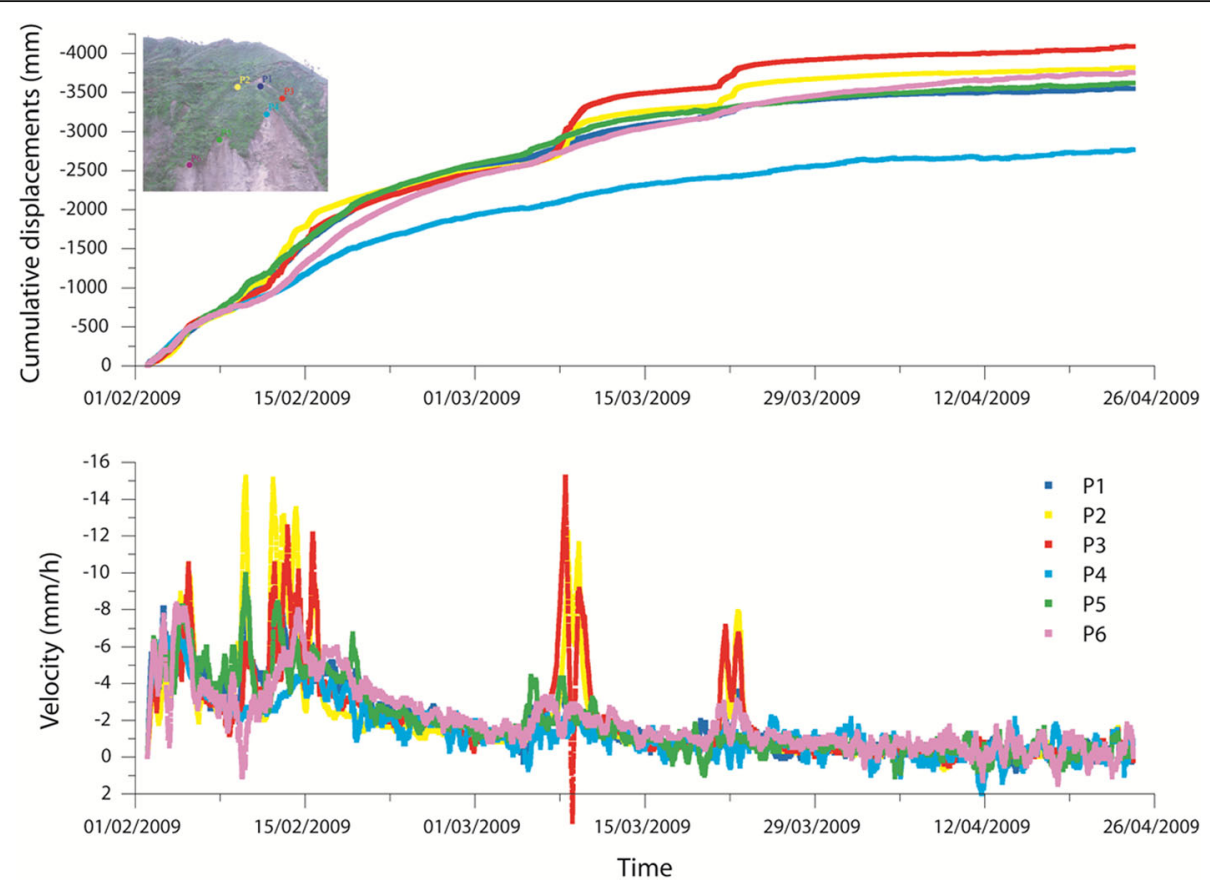

Fig. 12 Displacement and velocity time series of Santa Trada landslide obtained from the GB-InSAR system (after Del Ventisette et al., 2011)

limitations and the possibility of a synergic use for different applications (Table 4).

\section{Spaceborne platforms}

With the increasing large constellation of VHR satellites, imagery can be acquired timely after major landslide events and with daily temporal resolution at nearly global coverage. The main advantage of VHR imagery is the great density of spatial information, whereas, with more competing satellite operators entering the market, prices constantly decrease. A main advantage of optical datasets is their synergetic values for several other applications such as:

- post-disaster damage assessment;

- updating of land cover and landslide inventory maps;

- corresponding archives are often available over a given area.

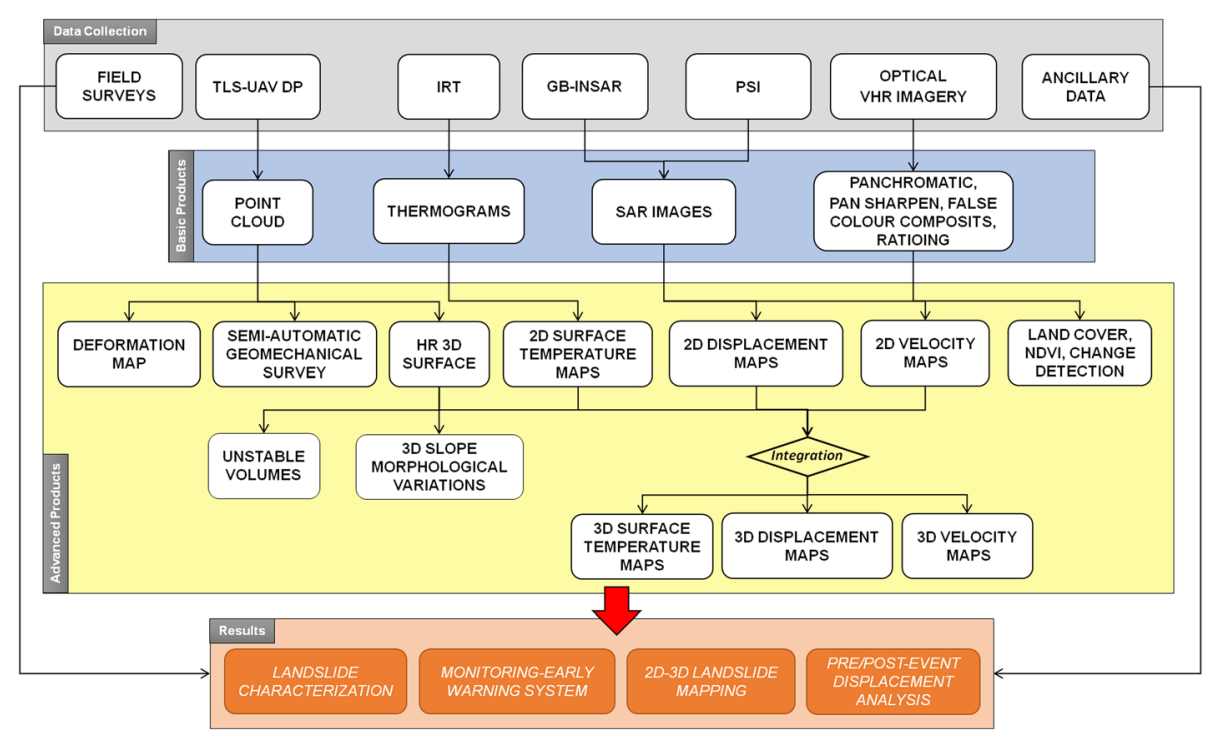

Fig. 13 Schematised workflow of the applied techniques showing the different degree of connection between the advanced products (coming from the available instrumentation) which are the basis for addressing the various landslides issues 
Table 4 Overview of advantages/limitations of the employed methods with respect to landslide type and analysis context

\begin{tabular}{|c|c|c|c|c|c|}
\hline $\begin{array}{l}\text { Remote sensing } \\
\text { technique }\end{array}$ & $\begin{array}{l}\text { Case } \\
\text { study }\end{array}$ & $\begin{array}{l}\text { Instability } \\
\text { process type }\end{array}$ & $\begin{array}{l}\text { Type of } \\
\text { application }\end{array}$ & Advantages & Drawbacks \\
\hline $\begin{array}{l}\text { Optical VHR } \\
\text { (OOA) }\end{array}$ & Giampilieri & $\begin{array}{l}\text { Shallow } \\
\text { soil slides - } \\
\text { Debris flows }\end{array}$ & $\begin{array}{l}\text { Landslide } \\
\text { mapping }\end{array}$ & $\begin{array}{l}\text { i) great density of spatial information, } \\
\text { ii) numerous platforms, iii) high spatial, } \\
\text { temporal and spectral resolution, } \\
\text { iv) OOA approaches able to delineate } \\
\text { areas affected by landslides }\end{array}$ & $\begin{array}{l}\text { i) high cost; ii) on-demand acquisition; } \\
\text { iii) cloud cover; iv) acquisition limited } \\
\text { to daylight, v) OOA thresholds } \\
\text { definition between changed and } \\
\text { unchanged areas }\end{array}$ \\
\hline $\begin{array}{l}\text { Spaceborne SAR } \\
\text { (PSI) }\end{array}$ & $\begin{array}{l}\text { Nebrodi e } \\
\text { Peloritani }\end{array}$ & $\begin{array}{l}\text { Complex, } \\
\text { rotational and } \\
\text { deep-seated } \\
\text { landslides }\end{array}$ & $\begin{array}{l}\text { Landslide } \\
\text { detection } \\
\text { and mapping }\end{array}$ & $\begin{array}{l}\text { i) good cost/benefit ratio, ii) coverage } \\
\text { of wide areas; iii) millimeter accuracy; } \\
\text { iv) availability of historical archives } \\
\text { (since 1992); v) day-night and all } \\
\text { weather acquisition. }\end{array}$ & $\begin{array}{l}\text { i) detection of fast movements; } \\
\text { ii) monitoring in deferred time; } \\
\text { iii) presence of dense vegetation } \\
\text { cover; iv) geometric distortions; } \\
\text { v) unusable to detect N-S oriented } \\
\text { landslides. }\end{array}$ \\
\hline UAV-DP & Ricasoli & $\begin{array}{l}\text { Shallow } \\
\text { landslides }\end{array}$ & $\begin{array}{l}\text { Landslide } \\
\text { characterization } \\
\text { and mapping }\end{array}$ & $\begin{array}{l}\text { i) Low cost, rapid survey; ii) high repeatability; } \\
\text { iii) high resolution data; iv) avoidance } \\
\text { of shadowing effects. }\end{array}$ & $\begin{array}{l}\text { i) Restrictive UAV flight regulations; } \\
\text { ii) skilled operator required; } \\
\text { iii) negative effect of vegetation } \\
\text { on the point cloud. }\end{array}$ \\
\hline TLS - IRT & $\begin{array}{l}\text { Elba } \\
\text { island }\end{array}$ & Rock slides & $\begin{array}{l}\text { Landslide } \\
\text { risk scenario } \\
\text { assessment }\end{array}$ & $\begin{array}{l}\text { i) Favorable logistic conditions (up-close } \\
\text { survey); ii) Rapid } 3 D \text { surface, geo-structural } \\
\text { and geo-mechanical survey; iii) detailed } \\
\text { unstable masses detection-volume } \\
\text { calculation. }\end{array}$ & $\begin{array}{l}\text { TLS: i) point cloud resolution related } \\
\text { to scenario distance; ii) negative } \\
\text { effect of vegetation on the point } \\
\text { cloud. IRT: iii) scenario thermal } \\
\text { contrasts related to slope } \\
\text { orientation-roughness and solar } \\
\text { radiation (daily/seasonal variations). }\end{array}$ \\
\hline $\begin{array}{l}\text { GB-InSAR - } \\
\text { TLS - IRT }\end{array}$ & San Leo & Rock fall & $\begin{array}{l}\text { Landslide } \\
\text { long-term } \\
\text { monitoring }\end{array}$ & $\begin{array}{l}\text { i) Multi-system approach for wide range } \\
\text { of instability process detection and analysis; } \\
\text { GB-InSAR: ii) millimeter accuracy; } \\
\text { iii) continuous monitoring. iv) day-night } \\
\text { and all weather acquisition. }\end{array}$ & $\begin{array}{l}\text { i) Intrinsic limitation of each adopted } \\
\text { technique (L.O.S, range of detectable } \\
\text { velocity, repetition time). IRT-TLS: } \\
\text { ii) only periodical check. GB-InSAR: } \\
\text { iii) uncapability for detecting rapid } \\
\text { and perpendicular displacements } \\
\text { with respect to the L.O.S.; } \\
\text { iv) ambiguity in locating } \\
\text { displacements for overhanging- } \\
\text { slope sectors. }\end{array}$ \\
\hline GB-InSAR & $\begin{array}{l}\text { Santa } \\
\text { Trada }\end{array}$ & $\begin{array}{l}\text { Translational } \\
\text { slide }\end{array}$ & $\begin{array}{l}\text { Landslide } \\
\text { Emergency } \\
\text { management }\end{array}$ & $\begin{array}{l}\text { i) Rapid installation; ii) day-night and all } \\
\text { weather acquisition; iii) early warning } \\
\text { and rapid assessment of risk scenario. }\end{array}$ & $\begin{array}{l}\text { i) System loss of coherence, spatial } \\
\text { and temporal decorrelation due } \\
\text { to vegetation cover; ii) not favorable } \\
\text { alignment between system L.O.S. } \\
\text { and landslide movement direction } \\
\text { (only 15-35\% of displacement } \\
\text { detected). }\end{array}$ \\
\hline
\end{tabular}

A greater diversity of platforms increases the chance to acquire cloud free imagery of a given area with a specified time frame; nevertheless atmospheric conditions remain an important factor that, depending on the climate zone and the season, may delay the acquisition of suitable images. For these reasons, satellite tasked for images with sub-meter resolution can still be associated with considerable costs. Higher spatial, spectral (e.g. WorldView-2) and temporal resolutions strongly increase the computational load for the storage and analysis of the datasets, especially for mapping over wide areas. This can considerably slow down the analysis and may need for further investments in hardware and software. This is closely related to the desirable exploitation of spatial context which is typically computational intensive. Pixel-based change detection (typically image differencing) is relatively easy to apply and can be accurate when most of surface changes are caused by landslides.
In many cases, it might also be possible to account for sensor and illumination differences by cross calibration and image transformation. However, only limited accuracy can be expected from such approaches in situation where other similar surface changes such as deforestation or barren fields are present in the same scene. The selection of an appropriate threshold to distinguish between changed and unchanged areas remains as a general difficulty for the application of pixel-based methods. Further problems are usually encountered when pixel-base change detection is applied on VHR imagery because of the higher spectral variance and stronger impacts of small co-registration errors. Due to a better exploitation of the spatial context within remote sensing images, OOA approaches generally yield better results than could be achieved with per pixel analyses. It has been demonstrated that OOA rule sets are not only capable to accurately delineate areas affected by 
landslides but can also be used to distinguish among different landslide types (Martha et al. 2010). In the study area of Giampilieri (Lu et al., 2011) the OOA approach has proved an effective tool to map rapid landslides, and support the local authorities and civil protection department for the emergency management. For both the obtained number and spatial extent of detected landslides, the results show a lower producer's accuracy than user's accuracy: specifically, ca. $31 \%$ of all manually mapped landslides were omitted in the OOA based detection. This indicates an overestimation of false positives during their classification, accompanied with an underestimation of true positives obtained from the membership function of the selected samples. Further improvements should include a more accurate definition of these thresholds for classifying false positives and a more careful selection of representative samples.

As discussed by Colesanti \& Wasowski (2006), due to the inherent limitations of current space observation systems and relevant data processing techniques, the practical applicability of Persistent Scatterer Interferometry (PSI) approaches is usually limited to two landslide classes of the Cruden \& Varnes (1996) classification: extremely slow and very slow movements (vel $<16 \mathrm{~mm} /$ year and $16 \mathrm{~mm} /$ year $\leq$ vel $<1.6 \mathrm{~m} /$ year, respectively). These phenomena are suitable for analysis based on PSI techniques, as long as they evolve with very low displacement rates (few tens of centimeters per year) and their velocities do not exceed the intrinsic limits of the techniques (related to the radar wavelength, revisiting time of the platform and the spatial density of measurement points). Moreover, landslide-induced displacements, detectable through PSI techniques, are restricted to "coherent" landslides with very slow dynamics, i.e. with little internal deformation such as deep-seated deformations (García-Davalillo et al, 2014), creep (Cascini et al., 2010), and, in some cases, slides (Raspini et al., 2015b) roto-translational slides (Tofani et al. 2013a, b), rockslide (Lauknes et al., 2010), complex landslides (Bardi et al., 2014), slow earth flows (Herrera et al., 2011) and badlands (Herrera et al., 2009). InSAR data can provide useful information about preevent movements, often characterized by low displacement rates (few $\mathrm{cm}$ /year) persisting over long time periods (Bardi et al., 2016; Frodella et al., 2016). This deformation regime is quite different to failure events, which occur suddenly and may produce ground displacements of several meters (Raspini et al., 2015a).

With reference to landslide detection/mapping the most advantageous aspects of the multipass D-InSAR approach are (Colesanti and Wasowski, 2006):

- The cost-effectiveness for wide-area (hundreds and thousands of $\mathrm{km}^{2}$ ) applications, typical of spaceborne remotely sensed data.
- The high density of benchmarks (up to several hundreds per $\mathrm{km}^{2}$ ).

- The use of "natural" benchmarks not requiring deployment and maintenance.

- The possibility of geo-locating the benchmarks with a precision in the order of 1-5 meters.

- The availability of the extremely valuable ESA (European Space Agency) ERS archive spanning about 20 years, which enables to carry out retrospective studies.

Recent studies proved the feasibility of combining (stitching) SAR data acquired by different sensors (e.g., ENVISAT with ERS, or RADARSAT-1 with RADARSAT-2), despite slight differences in critical image acquisition parameters. Regular revisiting time in the order of 20-40 days (up to 6 days with the new Sentinel-1 ESA mission).

On the whole, the case studies described in the scientific literature highlight that with reference to the detection/mapping of slow-moving landslide phenomena the main benefits regard:

- the definition of the boundaries of already detected mass movements;

- the definition of the states of activity;

- the detection of previously unmapped unstable areas.

However, several limiting factors need to be properly taken into account (Colesanti and Wasowski, 2006):

- Displacement data represent the one-dimensional projection along the LOS projection of a deformation that can actually occur in all three dimensions.

- The ambiguity of phase measurements implies the impossibility to track correctly (i.e., unambiguously) the relative LOS displacement between two scatterers exceeding $\lambda / 4(=1.4 \mathrm{~cm}$ for ERS) within one revisiting time interval ( 35 days for ERS), i.e. approximately $14.5 \mathrm{~cm} / \mathrm{yr}$. In practice, it is extremely difficult to detect LOS displacement rates exceeding $8-10 \mathrm{~cm} / \mathrm{yr}$ in the presence of low density of stable scatterers, such as in the case of landslides where topography and vegetation introduce a limitation in the number of detected scatterers. This limits the use of multi-interferometric approaches only to landslides ranging from extremely to very slow phenomena according to the velocity classification of Cruden and Varnes (1996).

- Limited versatility in terms of (a) positioning of the measurement points and (b) revisiting time. Both factors (a) and (b) cannot be optimized as degrees of freedom while planning an analysis.

- Finally, it is still difficult to forecast the coherent pixel density in rural areas without carrying out at 
least several processing steps on a significant number (15-20) of SAR images.

\section{UAV and Ground-based methods}

In terrestrial applications it is still necessary to perform time-consuming and hazardous activities, such as placing ground control points on the analysed scenario (Stavroulaki et al., 2016), if not supported by other technologies (Forlani et al., 2014). In this framework UAV photogrammetry has the following advantages: real-time, flexibility, high-resolution, low costs, as it allows the collection of information in dangerous environments without risk (Chang-chun et al. 2011). Furthermore, the recent development of new algorithms for digital photogrammetry, based on Structure from Motion (SfM) (Westoby et al. 2012) and Multi-View Stereo (MVS) (James and Robson, 2012) techniques, allows obtaining high-resolution 3D models, even by using compact and consumer-grade digital cameras (Lucieer et al., 2013; Rossi et al., 2016). In the case of landslide monitoring and characterization, acquiring aerial imagery using drones permits to overcome some limits of groundbased photogrammetric surveying, such as shadowing effects, which can drastically reduce the accuracy of the resulting digital models.

The synergic use of TLS and IRT has been applied at Elba island case study (section 3.2.1). The TLS survey yielded a detailed 3-D remote structural, geometrical, and geomechanical characterization of the investigated rock masses. In particular, a semiautomatic geomechanical survey made possible the automatic calculation of six of the ten parameters suggested by ISRM (1985) for the quantitative description of discontinuities (orientation, spacing, persistence, roughness, number of sets, and block size). A total of 1359 planes were recognized and clustered according to seven different discontinuity sets, adding two more discontinuity sets to the five detected by means of the traditional field survey, therefore improving the rock mass structural-geomechanical characterization (Fig. 7). The obtained TLS 3-D products also provided reference morphological maps useful for both further detailed field inspections and the design of possible future restoration works. The proposed approach proved to be an effective tool in the field of emergency management, when it is often urgently necessary and gather all the required information (characterization and mapping) as fast as possible in dangerous environments.

The investigated area showed favorable logistic conditions; in fact, the roadway at the foot of the investigated rock slope was fundamental in carrying out up-close the field inspections, the TLS, and the TIR surveys. Had this condition not existed, the point cloud resolution would not probably have been high enough for such detailed analyses. In San Leo an integrated use of GB-InSAR, TLS and IRT has been applied for landslide monitoring (section 3.2.2). The GB-InSAR one year monitoring campaign allowed analysing the short-term behavior of the 2014 rockfall event deposits (Frodella et al., 2016). A general stability of the town monitored structures and analysed rock wall was assessed, and 4 critical sectors were detected in the monitored area by means of $2 \mathrm{D}$ displacement maps, while 7 acceleration events were detected from the GB-InSAR control points time series. The accuracy in locating a GBInSAR control point is controlled by the system azimuth and range resolutions, which are in terms related to the distance between the sensor and the backscattering objects. Regarding the San Leo case study, the investigated rock wall has a subvertical geometry which in some portions shows overhanging sectors; in this framework, the GB-InSAR system installation frontal with respect to the surveyed scenario, lead to a different range resolution of scenario sectors located at different heights along the surveyed rock wall (Fig. 10). The obtained 3D displacement map in fact shows an ambiguity in locating deformation sectors along the rock wall height; therefore, in this specific case study sectors characterized by displacements are displayed as vertical zones instead of pixel clusters located at the cliff bottom (Fig. 9). The 3D GB-InSAR displacement map was also used for a comparison between TLS and GB-InSAR displacement data. The difference in the recorded displacements detected by the two monitoring systems in correspondence of the detected rock block toppling is related to the different displacement components of the recorded movements, due to the two different monitoring systems LOSs. The analyzed rock cliff is characterized by complex geomorphological and geometric features, different ongoing landslide processes with various state of activity. Each single employed monitoring technique can be considered not adequate for their intrinsic limitations. The combined use of the abovementioned techniques provided an effective monitoring system for landslide characterization and state of activity monitoring, thanks to the different instrument characteristics (LOS, range of detectable velocity, repetition time), which allowed to overcome the limitations of each single employed technique. Compared to GB-InSAR, TLS does not suffer from problematics such as loss of coherence, decorrelation, and displacement detection capability only along the sensor LOS; on the other hand, GB-InSAR single measure can reach sub-millimeter accuracy, while using a TLS it is not possible to easily detect displacements smaller than $10 \mathrm{~mm}$. Therefore, TLS was considered more suitable for the detection, characterization and volume assessment of the minor rockfall events affecting the newly formed cliff (too fast phenomena to be detected by means of the GB-InSAR 
system). In both the abovementioned case studies, the capability to remotely collect the scenario surface temperature at a detailed spatial resolution proved that IRT can be usefully applied in the field landslide analyses. Nevertheless, IRT alone is insufficient for a complete landslide characterization; in order to obtain a more accurate interpretation of the results IRT could be more profitably used as an ancillary low cost technique through the integration with other ground based remote sensing techniques, such as TLS and GB-InSAR. Future developments should include the application of fixed IRT installations for gathering continuous, highresolution, real-time data to be compared with those of the integrated GB-InSAR and TLS monitoring systems. Furthermore, the portability of modern thermal cameras and the rapid evolution of IRT technology opens up future scenarios of automated inspections, which could be quickened by using remotely controlled UAV platforms. The Santa Trada landslide offers a good example of GBInSAR application in emergency conditions in order to assess the risk impending on a critical infrastructure. In Santa Trada area, a GB-InSAR device was promptly installed in order to understand the temporal evolution of a landslide that seriously threatened the functionality and the safety of a strategic road infrastructure. This technique worked with all weather conditions and with a continuous surveillance for all the time of emergency, allowing the rapid assessment of the overall dynamics of the instable slope and related risks scenarios. This application was among the first to demonstrate the full effectiveness of this system in managing landslides emergencies since it greatly facilitated the intervention operations by designated authorities that aimed to restore a normal service in the shortest possible time after a precautionary closure of the motorway. It also granted the possibility to acquire data during precipitations, which represent the most critical moment in stability terms; indeed, usually traditional monitoring instruments are not able to work in such conditions and to provide such useful information real-time, since they normally require a longer time for the installation and a direct access to the unstable and unsafe sites. The GB-InSAR technique proved to be a suitable and versatile tool to assess the actual hazard of the landslide in order to enable the re-opening of the motorway.

\section{Conclusions}

In the recent years, remote sensing techniques for landslide analysis have been interested by several technical and scientific improvements. These techniques can play an important role in landslide risk management, as they allow the representation of large surfaces with dense spatial sampling, offering clear advantages with respect to traditional topographical systems (such as GPSs and robotized total stations), which on the contrary provide data that are accurate but necessarily limited to a small number of control points (Teza et al., 2008). Currently landslide analysis operators can select the most proper methodology with respect to their specific needs, which can be related to the different civil protection phases, technical issues, financial budget, environmental factors and specific features of the studied instability phenomena. The selection of the proper methodology to be adopted can be related to technical issues, economic budget, environmental factors and specific feature of the landslides to be monitored. Because of a growing demand for effective Civil Protection procedures in pre- and postdisaster initiatives in landslide-prone areas, the purpose of researchers in the near future is to improve the investigative capacity of the such instruments and consequently to extend their fields of application. In fact, landslides managing in order to reduce vulnerability is currently considered more feasible (in terms of faster and extensive results) than governing all the natural conditions leading to instability, such as the spatial distribution of geology and geomorphology and the climatic influence.

\section{Authors' contributions}

NC conceived and structured the whole manuscript. He also supervised the writing, especially during the organization of contributions coming from different techniques. WF, SM, El were responsible for the preparation of the ground-based sections. VT, AC, FR, PL were responsible for the preparation of the spaceborne sections. GR and LT were responsible for the preparation of the UAV sections. All authors read and approved the final manuscript.

\section{Competing interests}

The authors declare that they have no competing interests.

\section{Author details}

${ }^{1}$ Department of Earth Sciences, University of Florence, Via G. La Pira 4, 50121 Florence, Italy. ${ }^{2}$ College of Surveying and Geo-Informatics, Tongji University, Shanghai 200092, China.

Received: 17 November 2016 Accepted: 22 February 2017

Published online: 07 March 2017

\section{References}

Abellán, A., J.M. Vilaplana, and J. Martínez. 2006. Application of a long-range terrestrial laser scanner to a detailed rockfall study at Vall de Núria (Eastern pyrenees, Spain). Engineering Geology 88: 136-148.

Abellán, A., J.M. Vilaplana, J. Calvet, D. Garcı-Selles, and E. Asensio. 2011. Rockfall monitoring by Terrestrial Laser Scanning - case study of the basaltic rock face at Castellfollit de la Roca (Catalonia, Spain). Natural Hazards and Earth System Sciences 11: 829-841.

Adam, N., F. Rodriguez-Gonzalez, A. Parizzi, and W. Liebhart. 2011. Wide area persistent scatterer interferometry. In Geoscience and Remote Sensing Symposium (IGARSS), 2011 IEEE International, 1481-1484.

Agisoft LLC. 2016. Agisoft PhotoScan Professional v. 1.2.4.. available at http://www. agisoft.com.

Ardizzone, F., G. Basile, M. Cardinali, N. Casagli, S. Del Conte, C. Del Ventisette, F. Fioruccia, F. Garfagnoli, G. Gigli, F. Guzzetti, G. lovine, A.C. Mondini, S. Moretti, M. Panebianco, F. Raspini, P. Reichenbach, M. Rossi, L. Tanteri, and O. Terranova. 2012. Landslide inventory map for the Briga and the Giampilieri catchments, NE Sicily, Italy. Journal of Maps 8(2): 176-180.

Bamler, R., and P. Hartl. 1998. Synthetic aperture radar interferometry. Inverse Problems 14: 1-54.

Bardi, F., W. Frodella, A. Ciampalini, S. Bianchini, C. Del Ventisette, G. Gigli, R. Fanti, S. Moretti, G. Basile, and N. Casagli. 2014. Integration between ground based and satellite SAR data in landslide mapping: the San Fratello case study. Geomorphology 223: 45-60. 
Bardi, F., F. Raspini, A. Ciampalini, L. Kristensen, L. Rouyet, T.R. Lauknes, R. Frauenfelder, and N. Casagli. 2016. Space-borne and ground-based InSAR data integration: the Åknes test site. Remote Sensing 8(3): 237.

Barla, G., F. Antolini, and G. Gigli. 2016. 3D Laser scanner and thermography for tunnel discontinuity mapping. Geomechanics and Tunnelling 9(1): 29-36.

Baroň, I., D. Bečkovský, and L. Míča. 2012. Application of infrared thermography for mapping open fractures in deep-seated rockslides and unstable cliffs. Landslides 11(1): 15-27.

Berardino, P., G. Fornaro, R. Lanari, and E. Sansosti. 2002. A new algorithm for surface deformation monitoring based on small baseline differential SAR interferograms. IEEE Transactions on Geoscience and Remote Sensing 40(11): 2375-2383.

Berardino, P., M. Costantini, G. Franceschetti, A. lodice, L. Pietranera, and V. Rizzo. 2003. Use of differential SAR interferometry in monitoring and modelling large slope instability at Maratea (Basilicata, Italy). Engineering Geology 68(1-2): 31-51.

Berti, M., A. Corsini, S. Franceschini, and J.P. lannacone. 2013. Automated classification of Persistent Scatterers Interferometry time series. Natural Hazards and Earth System Sciences 13(8): 1945-1958.

Bianchini, S., F. Cigna, G. Righini, C. Proietti, and N. Casagli. 2012. Landslide hotspot mapping by means of persistent scatterer interferometry. Environmental Earth Sciences 67(4): 1155-1172.

Bianchini, S., F. Pratesi, T. Nolesini, and N. Casagli. 2015. Building deformation assessment by means of persistent scatterer interferometry analysis on a landslide-affected area: the Volterra (Italy) case study. Remote Sensing 7(4): 4678-4701.

Brunetti, M.T., Z. Xiao, G. Komatsu, S. Peruccacci, and F. Guzzetti. 2015. Terrestrial and extraterrestrial landslide size statistics. In European Planetary Science Congress 2015, 27 September-2 October 2015, Nantes, France. Copernicus. org/ EPSC2015, id. EPSC2015-776, vol. 10, 776.

Bürgmann, R., G. Hilley, A. Ferretti, and F. Novali. 2005. Resolving vertical tectonics in the San Francisco Bay area from permanent scatterer InSAR and GPS analysis. Geology 34: 221-224.

Calvari, S., E. Intrieri, F. Di Traglia, A. Bonaccorso, N. Casagli, and A. Cristaldi. 2016. Monitoring crater-wall collapse at open-conduit volcanoes: the case study of the 12 January 2013 event at Stromboli. Bulletin of Volcanology 78(39): 1-16.

Canuti, P., N. Casagli, L. Ermini, R. Fanti, and P. Farina. 2004. Landslide activity as a geoindicator in Italy: significance and new perspectives from remote sensing. Environmental Geology 45: 907-919.

Canuti, P., N. Casagli, F. Catani, G. Falorni, and P. Farina. 2007. Integration of remote sensing techniques in different stages of landslide response. In Progress in landslide science, 251-260. Berlin Heidelberg: Springer.

Cardenal, J., E. Mata, J.L. Perez-Garcia, J. Delgado, M. Andez, A. Gonzalez, and J.R. Diaz-de-Teran. 2008. Close range digital photogrammetry techniques applied to landslide monitoring. International Archives of Photogrammetry. Remote Sensing and Spatial Information Sciences 37;part B8:235-240.

Casagli, N., R. Fanti, M. Nocentini, and G. Righini. 2005. Assessing the capabilities of VHR satellite data for debris flow mapping in the Machu Picchu area (C101-1). In Landslides, 61-70. Berlin Heidelberg: Springer.

Casagli, N., F. Catani, C. Del Ventisette, and G. Luzi. 2010. Monitoring, prediction, and early warning using ground-based radar interferometry. Landslides 7(3): 291-301.

Cascini, L., G. Fornaro, and D. Peduto. 2010. Advanced low-and full-resolution DInSAR map generation for slow-moving landslide analysis at different scales. Engineering Geology 112(1): 29-42.

Casu, F., M. Manzo, and R.A. Lanari. 2006. Quantitative assessment of the SBAS algorithm performance for surface deformation retrieval. Remote Sensing of Environment 102: 195-210

Chandler, J. 1999. Effective application of automated digital photogrammetry for geomorphological research. Earth Surface Processes and Landforms 24: 51-63.

Chang-chun, L., Z. Guang-Sheng, L. Tian-jie, and G. A-du. 2011. Quick imageprocessing method of UAV without control points data in earthquake disaster area. Transactions of the Nonferrous Metals Society of China 21: 523-528.

Cheng, K.S., C. Wei, and S.C. Chang. 2004. Locating landslides using multitemporal satellite images. Advances in Space Research 33: 296-301.

Chini, M., F.R. Cinti, and S. Stramondo. 2011. Co-seismic surface effects from very high resolution panchromatic images: the case of the 2005 Kashmir (Pakistan) earthquake. Natural Hazards and Earth System Sciences 11: 931-943.

Ciampalini, A., F. Garfagnoli, B. Antonielli, C. Del Ventisette, and S. Moretti. 2012. Photo-lithological map of the southern flank of the Tindouf Basin (Western Sahara). Journal of Maps 8: 453-464.

Ciampalini, A., F. Bardi, S. Bianchini, W. Frodella, C. Del Ventisette, S. Moretti, and N. Casagli. 2014. Analysis of building deformation in landslide area using multisensor PSInSAR ${ }^{\mathrm{TM}}$ technique. International Journal of Applied Earth Observation and Geoinformation 33: 166-180.

Ciampalini, A., F. Raspini, S. Bianchini, W. Frodella, F. Bardi, D. Lagomarsino, F. Di Traglia, S. Moretti, C. Proietti, P. Pagliara, R. Onori, A. Corazza, A. Duro, G. Basile, and N. Casagli. 2015a. Remote sensing as tool for development of landslide databases: The case of the Messina Province (Italy) geodatabase. Geomorphology 249: 103-118.

Ciampalini, A., F. Raspini, and S. Moretti. 2015b. Landslide back monitoring and forecasting by using PSInSAR technique: the case of Naso (Sicily, Southern Italy). Atti Soc. Tosc. Sci. Nat., Mem., Serie A 122. doi:10.2424/ASTSN.M.2015.16.

Ciampalini, A., F. Raspini, W. Frodella, F. Bardi, S. Bianchini, and S. Moretti. $2016 \mathrm{a}$. The effectiveness of high-resolution LiDAR data combined with PSInSAR data in landslide study. Landslides 13(2): 399-410.

Ciampalini, A., F. Raspini, D. Lagomarsino, F. Catani, and N. Casagli. 2016b. Landslide susceptibility map refinement using PSInSAR data. Remote Sensing of Environment 184: 302-315.

Colesanti, C., Ferretti, A., Prati, C., and Rocca, F. 2003. Monitoring landslides and tectonic motions with the Permanent Scatterers Technique. Engineering Geology, 68(1): 3-14.

Colesanti, C., and J. Wasowski. 2006. Investigating landslides with space-borne Synthetic Aperture Radar (SAR) interferometry. Engineering Geology 88: 173-199.

Colomina, I., and P. Molina. 2014. Unmanned aerial systems for photogrammetry and remote sensing: a review. ISPRS Journal of Photogrammetry and Remote Sensing 92: 79-97.

Costantini, M., S. Falco, F. Malvarosa, and F.A. Minati. 2008. New method for identification and analysis of Persistent Scatterers in series of SAR images. In Geoscience and Remote Sensing Symposium (IGARSS), 2008 IEEE International, vol. 2, 449-452.

Crosetto, M., E. Biescas, J. Duro, J. Closa, and A. Arnaud. 2008. Generation of advanced ERS and Envisat interferometric SAR products using the Stable Point Network technique. Photogrammetric Engineering \& Remote Sensing 2008(74): 443-451.

Crosetto, M., O. Monserrat, M. Cuevas-González, N. Devanthéry, and B. Crippa. 2016. Persistent scatterer interferometry: a review. ISPRS Journal of Photogrammetry and Remote Sensing 115: 78-89.

Cruden, D.M., and D.J. Varnes. 1996. Landslide types and processes. In Landslides: investigation and Mitigation, Sp. Rep. 247, Transportation Research Board, National Research Council, ed. A.K. Turner and R.L. Schuster, 36-75. Washington DC: National Academy Press.

Del Ventisette, C., E. Intrieri, G. Luzi, N. Casagli, R. Fanti, and D. Leva. 2011. Using ground based radar interferometry during emergency: the case of the A3 motorway (Calabria Region, Italy) threatened by a landslide. Natural Hazards and Earth System Sciences 11(9): 2483-2495.

Del Ventisette, C., F. Garfagnoli, A. Ciampalini, A. Battistini, G. Gigli, S. Moretti, and N. Casagli. 2012. An integrated approach to the study of catastrophic debrisflows: geological hazards and human influence. Natural Hazards and Earth System Sciences 12: 2907-2922.

Di Traglia, F., C. Del Ventisette, M. Rosi, F. Mugnai, E. Intrieri, S. Moretti, and N. Casagli. 2013. Ground-based InSAR reveals conduit pressurization pulses at Stromboli volcano. Terra Nova 25(3): 192-198.

Di Traglia, F., E. Intrieri, T. Nolesini, F. Bardi, C. Del Ventisette, F. Ferrigno, S. Frangioni, W. Frodella, G. Gigli, A. Lotti, C. Tacconi Stefanelli, L. Tanteri, D. Leva, and N. Casagli. 2014a. The ground-based InSAR monitoring system at Stromboli volcano: linking changes in displacement rate and intensity of persistent volcanic activity. Bulletin of Volcanology 76(2): 1-18.

Di Traglia, F., T. Nolesini, E. Intrieri, F. Mugnai, D. Leva, M. Rosi, and N. Casagli. 2014b. Review of ten years of volcano deformations recorded by the ground-based InSAR monitoring system at Stromboli volcano: a tool to mitigate volcano flank dynamics and intense volcanic activity. Earth-Science Reviews 139: 317-335.

Eisenbeiss, H., and M. Sauerbier. 2011. Investigation of UAV systems and flight modes for photogrammetric applications. The Photogrammetric Record 26(136): 400-421.

Eyers, R., J.M. Moore, J. Hervás, and J.G. Liu. 1998. Integrated use of Landsat TM and SPOT panchromatic imagery for landslide mapping: case histories from southeast Spain. Geological Society, London, Engineering Geology Special Publications January 1, 133-140.

Farina, P., N. Casagli, and A. Ferretti. 2008. Radar-interpretation of InSAR measurements for landslide investigations in civil protection practices. In Proceedings of 1st North American Landslide Conference, 272-283. Colorado: Vail.

Farina, P., L. Leoni, F. Babboni, F. Coppi, L. Mayer, and P. Ricci. 2011. IBIS-M, an innovative radar for monitoring slopes in open-pit mines. In Proc., Slope 
Stability 2011: International Symposium on Rock Slope Stability in Open Pit Mining and Civil Engineering, Vancouver (Canada), 18-21 September.

Ferrero, A.M., G. Forlani, R. Roncella, and H.I. Voyat. 2009. Advanced geostructural survey methods applied to rock mass characterization. Rock Mechanics and Rock Engineering 42: 631-665.

Ferretti, A., C. Prati, and F. Rocca. 2001. Permanent Scatterers in SAR interferometry. IEEE Transactions on Geoscience and Remote Sensing 39(1): 8-20.

Ferretti, A., A. Fumagalli, F. Novali, C. Prati, F. Rocca, and A. Rucci. 2011. A new algorithm for processing interferometric data-stacks: SqueeSAR ${ }^{\text {TM }}$. IEEE Transactions on Geoscience and Remote Sensing 49(9): 3460-3470.

Fiorucci, F., M. Cardinali, R. Carlà, R. Rossi, A.C. Mondini, L. Santurri, F. Ardizzone, and F. Guzzetti. 2011. Seasonal landslide mapping and estimation of landslide mobilization rates using aerial and satellite images. Geomorphology 129: 59-70.

Forlani, G., L. Pinto, R. Roncella, and D. Pagliari. 2014. Terrestrial photogrammetry without ground control points. Earth Science Informatics 7(2): 71-81.

Franceschi, M., G. Teza, N. Preto, A. Pesci, A. Galgaro, and S. Girardi. 2009. Discrimination between marls and limestones using intensity data from terrestrial laser scanner. ISPRS Journal of Photogrammetry 64: 522-528.

Frodella, W., and S. Morelli. 2013. High-resolution 3D geomechanical characterization for the evaluation of rockslide susceptibility scenarios. Rend Online Soc. Geol. It 24: 143-145. ISSN:2035-8008.

Frodella, W., S. Morelli, F. Fidolini, V. Pazzi, and R. Fanti. 2014a. Geomorphology of the Rotolon landslide (Veneto Region, Italy). Journal of Maps 10(3): 394-401. doi: http://dx.doi.org/10.1080/17445647.2013.869666

Frodella, W., S. Morelli, G. Gigli, and N. Casagli. 2014b. Contribution of infrared thermography to the slope instability characterization, Proceedings of World Landslide Forum 3, vol. 4, 144-147.. 2-6 June 2014, Beijing, China.

Frodella, W., F. Fidolini, S. Morelli, and F. Pazzi. 2015. Application of Infrared Thermography for landslide mapping: the Rotolon DSGDS case study. Rendiconti Online Societa Geologica Italiana 35: 144-147. doi:10.3301/ROL.2015.85.

Frodella, W., A. Ciampalini, G. Gigli, L. Lombardi, F. Raspini, M. Nocentini, C. Scardigli, and N. Casagli. 2016. Synergic use of satellite and ground based remote sensing methods for monitoring the San Leo rock cliff (Northern Italy). Geomorphology 264: 80-94.

Frohlich, C., and M. Mettenleiter. 2004. Terrestrial laser scanning: new perspectives in 3D surveying. In Laser Scanners for Forest and Landscape Assessment, 36. International Archives of Photogrammetry, Remote Sensing and Spatial Information Sciences, ed. M. Thies, B. Koch, H. Spiecker, and H. Weinacker, 8/W2.

Fruneau, B., J. Achache, and C. Delacourt. 1996. Observation and modeling of the Saint-Etienne-de-Tine'e Landslide using SAR interferometry. Tectonophysics 265.

García-Davalillo, J.C., G. Herrera, D. Notti, T. Strozzi, and I. Álvarez-Fernández. 2014. DInSAR analysis of ALOS PALSAR images for the assessment of very slow landslides: the Tena Valley case study. Landslides 11(2): 225-246.

Ghiglia, D.C., and L.A. Romero. 1994. Robust two-dimensional weighted and unweighted phase unwrapping that uses fast transforms and iterative methods. Journal of the Optical Society of America 11(1): 107-117.

Gigli, G., and N. Casagli. 2011. Semi-automatic extraction of rock mass structural data from high resolution LIDAR point clouds. International Journal of Rock Mechanics \& Mining Sciences 48: 187-198.

Gigli, G., F. Mugnai, L. Leoni, and N. Casagli. 2009. Analysis of deformations in historic urban areas using terrestrial laser scanning. Natural Hazards and Earth System Sciences 9: 1759-1761.

Gigli, G., W. Frodella, F. Mugnai, D. Tapete, F. Cigna, R. Fanti, E. Intrieri, and L. Lombardi. 2012. Instability mechanisms affecting cultural heritage sites in the Maltese Archipelago. Natural Hazards and Earth System Sciences 12: 1-21.

Gigli, G., W. Frodella, F. Garfagnoli, F. Mugnai, S. Morelli, F. Menna, and N. Casagli. 2014a. 3-D geomechanical rock mass characterization for the evaluation of rockslide susceptibility scenarios. Landslides 11(1): 131-140. doi:10.1007/ s10346-013-0424-2

Gigli, G., S. Morelli, S. Fornera, and N. Casagli. 2014b. Terrestrial laser scanner and geomechanical surveys for the rapid evaluation of rockfall susceptibility scenarios. Landslides 11(1): 1-14. doi:10.1007/s10346-012-0374-0.

Gigli, G., E. Intrieri, L. Lombardi, M. Nocentini, W. Frodella, M. Balducci, L.D. Venanti, and N. Casagli. 2014c. Event scenario analysis for the design of rockslide countermeasures. Journal of Mountain Science 11(6): 1521-1530.

Gopi, S. 2007. Advanced surveying: total station. Pearson Education India: GIS and Remote Sensing.

Grussenmeyer, P., T. Landes, T. Voegtle, and K. Ringle. 2008. Comparison methods of terrestrial laser scanning, photogrammetry and tacheometry data for recording of cultural heritage buildings. ISPRS Archives of Photogrammetry, Remote Sensing 37: W5.

Guzzetti, F., A. Mondini, M. Cardinali, F. Fiorucci, M. Santangelo, and K.T. Chang. 2012. Landslide inventory maps: new tools for an old problem. Earth Science Reviews 112: 42-66.

Hanssen, R.S. 2005. Satellite radar interferometry for deformation monitoring: a priori assessment of feasibility and accuracy. International Journal of Applied Earth Observation and Geoinformation 6: 253-260.

Hay, G.J., T. Blaschke, D.J. Marceau, and A. Bouchard. 2003. A comparison of three image-object methods for the multiscale analysis of landscape structure. ISPRS Journal of Photogrammetry and Remote Sensing 57(5): 327-345.

Herrera, G., J.C. Davalillo, J. Mulas, G. Cooksley, O. Monserrat, and V. Pancioli. 2009. Mapping and monitoring geomorphological processes in mountainous areas using PSI data: Central Pyrenees case study. Natural Hazards and Earth System Sciences 9: 1587-1598.

Herrera, G., D. Notti, J.C. Garcia-Davalillo, O. Mora, G. Cooksley, M. Sanchez, A. Arnaud, and M. Crosetto. 2011. Landslides analysis with C- and X-band satellite SAR data: the Portalet landslide area. Landslides 8: 195-206.

Hervas, J., J.I. Barredo, P.L. Rosin, A. Pasuto, F. Mantovani, and S. Silvano. 2003. Monitoring landslides from optical remotely sensed imagery: the case history of Tessina landslide, Italy. Geomorphology 54: 63-75.

Hilley, G.E., R. Bürgmann, A. Ferretti, F. Novali, and F. Rocca. 2004. Dynamics of slowmoving landslides from permanent scatterer analysis. Science 304(5679): 1952-1955.

Hooper, A., H.A. Zebker, P. Segall, and B. Kampes. 2004. A new method for measuring deformation on volcanoes and other natural terrains using InSAR persistent scatterers. Geophysical Research Letters 31(23).

Hooper, A., P. Segall, and H. Zebker. 2007. Persistent scatterer interferometric synthetic aperture radar for crustal deformation analysis, with application to Volcan Alcedo, Galapagos. Journal of Geophysical Research 112(B7): 1-21.

Hungr, O., S. Leroueil, and L. Picarelli. 2014. The Varnes classification of landslide types, an update. Landslides 11(2): 167-194.

Intrieri, E., G. Gigli, F. Mugnai, R. Fanti, and N. Casagli. 2012. Design and implementation of a landslide early warning system. Engineering Geology 147-148: 124-136.

Intrieri, E., F. Di Traglia, C. Del Ventisette, G. Gigli, F. Mugnai, G. Luzi, and N. Casagli. 2013. Flank instability of Stromboli volcano (Aeolian Islands, Southern Italy): Integration of GB-InSAR and geomorphological observations. Geomorphology 201: 60-69.

Intrieri, E., G. Gigli, M. Nocentini, L. Lombardi, F. Mugnai, and N. Casagli. 2015. Sinkhole monitoring and early warning: an experimental and successful GBInSAR application. Geomorphology 241: 304-314.

ISRM. 1985. Suggested methods for determining point load strength. International Journal of Rock Mechanics and Mining Sciences \& Geomechanics Abstracts 22(2): 51-62.

Jaboyedoff, M., R. Metzger, T. Oppikofer, R. Couture, M.H. Derron, J. Locat, and D. Turmel. 2007. New insight techniques to analyze rock-slope relief using DEM and 3D-imaging cloud points: COLTOP-3D software. In Rock mechanics: Meeting Society's Challenges and demands, vol. 1, 61-68.

Jaboyedoff, M., T. Oppikofer, A. Abellán, M.H. Derron, A. Loye, R. Metzger, and A. Pedrazzini. 2012. Use of LIDAR in landslide investigations: a review. Natural Hazards 61(1): 5-28.

James, M.R., and S. Robson. 2012. Straightforward reconstruction of 3D surfaces and topography with a camera: accuracy and geoscience application. Journal of Geophysical Research: Earth Surface 117(F3). doi:10.1029/2011JF002289.

Kimura, H., and Y. Yamaguchi. 2000. Detection of landslide areas using satellite radar interferometry. Photogrammetric Engineering and Remote Sensing 66(3): 337-344.

Kjekstad, O., and L. Highland. 2009. Economic and social impacts of landslides. In Landslides-disaster risk reduction, 573-587. Berlin, Heidelberg: Springer.

Kurtz, C., A. Stumpf, J.P. Malet, P. Gançarski, A. Puissant, and N. Passat. 2014. Hierarchical extraction of landslides from multiresolution remotely sensed optical images. ISPRS Journal of Photogrammetry and Remote Sensing 87: 122-136.

Lamri, T., S. Djemaï, M. Hamoudi, B. Zoheir, A. Bendaoud, K. Ouzegane, and M. Amara. 2016. Satellite imagery and airborne geophysics for geologic mapping of the Edembo area, Eastern Hoggar (Algerian Sahara). Journal of African Earth Sciences 115: 143-158.

Lanari, R., O. Mora, M. Manunta, J.J. Mallorqui, P. Berardino, and E. Sansosti. 2004 A small baseline approach for investigating deformation on full resolution differential SAR interferograms. IEEE Transactions on Geoscience and Remote Sensing 42: 1377-1386. 
Lane, S.N., T.D. James, and M.D. Crowell. 2000. Application of digital photogrammetry to complex topography for geomorphological research. Photogrammetric Record 16: 793-821.

Lauknes, T.R., A. Piyush Shanker, J.F. Dehls, H.A. Zebker, I.H.C. Henderson, and Y Larsen. 2010. Detailed rockslide mapping in northern Norway with small baseline and persistent scatterer interferometric SAR time series methods. Remote Sensing of Environment 114: 2097-2109.

Lillesand, T., R.W. Kiefer, and J. Chipman. 2014. Remote sensing and image interpretation. Wiley. pp. 736

Lin, C.Y., H.M. Lo, W.C. Chou, and W.T. Lin. 2004. Vegetation recovery assessment on the Jou-Jou Mountain landslide area caused by the 921 earthquake in the Central Taiwan. Ecological Modeling 176: 75-81.

Lombardi, L., M. Nocentini, W. Frodella, T. Nolesini, F. Bardi, E. Intrieri, T. Carlà, L. Solari, G. Dotta, F. Ferrigno, and N. Casagli. 2016. The Calatabiano landslide (Southern Italy): preliminary GB-InSAR monitoring data and remote 3D mapping. Landslides: 1-12. doi:10.1007/s10346-016-0767-6.

Lu, P., A. Stumpf, N. Kerle, and N. Casagli. 2011. Object-oriented change detection for landslide rapid mapping. Geoscience and Remote Sensing Letters 8: 701-705.

Lu, P., N. Casagli, F. Catani, and V. Tofani. 2012. Persistent Scatterers Interferometry Hotspot and Cluster Analysis (PSI-HCA) for detection of extremely slow-moving landslides. International Journal of Remote Sensing 33(2): 466-489. doi: http://dx.doi.org/10.1080/01431161.2010.536185.

Lucieer, A., S. De Jong, and D. Turner. 2013. Mapping landslide displacements using Structure from Motion (SFM) and image correlation of multi-temporal UAV photography. Progress in Physical Geography 38(1): 97-116.

Luzi, G., M. Pieraccini, D. Mecatti, L. Noferini, G. Guidi, F. Moia, and C. Atzeni. 2004 Ground-based radar interferometry for landslides monitoring: atmospheric and instrumental decorrelation sources on experimental data. IEEE Transactions on Geoscience and Remote Sensing 42(11): 2454-2466.

Luzi, G., O. Monserrat, M. Crosetto, R. Copons, and J. Altimir. 2010. Ground-based SAR interferometry applied to landslide monitoring in mountainous areas, 2426. Mountain Risks Conference: Bringing Science to Society, Firenze, Italy.

Ma, H.R., X. Cheng, L. Chen, H. Zhang, and H. Xiong. 2016. Automatic identification of shallow landslides based on Worldview2 remote sensing images. Journal of Applied Remote Sensing 10(1): 016008. doi:10.1117/1.JRS.10.016008.

Maldague, X. 2001. Theory and practice of infrared technology for non destructive testing. John-Wiley \&: Sons. 684 p.

Mantovani, F., R. Soeters, and C.J. van Westen. 1996. Remote sensing techniques for landslide studies and hazard zonation in Europe. Geomorphology 15: 213-225.

Marcelino, E.V., A.R. Formaggio, and E.E. Maeda. 2009. Landslide inventory using image fusion techniques in Brazil. International Journal of Applied Earth Observation and Geoinformation 11: 181-191.

Martha, T.R., and N. Kerle. 2012. Creation of event-based landslide inventory from panchromatic images by object oriented analysis. Proceedings of the 4th GEOBIA, May 7-9, 2012 - Rio de Janeiro - Brazil, 053

Martha, T.R., N. Kerle, V. Jetten, C.J. van Westen, and K.V. Kumar. 2010. Characterizing spectral, spatial and morphometric properties of landslides for semi-automatic detection using object-oriented methods. Geomorphology 116: $24-36$

Massonnet, D., and K.L. Feigl. 1998. Radar interferometry and its application to changes in the earth's surface. Reviews of Geophysics 36: 441-500.

Meisina, C., F. Zucca, D. Notti, A. Colombo, A. Cucchi, G. Savio, C. Giannico, and M. Bianchi. 2008. Geological interpretation of PSInSAR data at regional scale. Sensors 8(11): 7469-7492.

Meisina, C., D. Notti, F. Zucca, M. Ceriani, A. Colombo, F. Poggi, A. Roccati, and A. Zaccone. 2013. The use of PSInSAR ${ }^{T M}$ and SqueeSAR ${ }^{T M}$ techniques for updating landslide inventories. In Landslide science and practice, ed. C. Margottini, P. Canuti, and K. Sassa, 81-87. Berlin Heidelberg: Springer.

Metternicht, G., L. Hurni, and R. Gogu. 2005. Remote sensing of landslides: an analysis of the potential contribution to geo-spatial systems for hazard assessment in mountain environments. Remote Sensing of Environment 98: 284-303.

Mineo, S., and G. Pappalardo. 2016. The use of infrared thermography for porosity assessment of intact rock. Rock mechanics and rock engineering, 1-13.

Mineo, S., G. Pappalardo, F. Rapisarda, A. Cubito, and G. Di Maria. 2015. Integrated geostructural, seismic and infrared thermography surveys for the study of an unstable rock slope in the Peloritani Chain (NE Sicily). Engineering Geology 195: 225-235

Mondini, A.C., F. Guzzetti, P. Reichenbach, M. Rossi, M. Cardinali, and F. Ardizzone. 2011. Semi-automatic recognition and mapping of rainfall induced shallow landslides using optical satellite images. Remote Sensing of Environment 115 1743-1757.
Mondini, A.C., A. Viero, M. Cavalli, L. Marchi, G. Herrera, and F. Guzzetti. 2014. Comparison of event landslide inventories: the Pogliaschina catchment test case, Italy. Natural Hazards and Earth System Discussion 2: 1093-1125.

Monserrat, O., M. Crosetto, and G. Luzi. 2014. A review of ground-based SAR interferometry for deformation measurement. ISPRS Journal of Photogrammetry and Remote Sensing 93: 40-48.

Mora, O., J.J. Mallorqui, and A. Broquetas. 2006. Linear and nonlinear terrain deformation maps from a reduced set of interferometric SAR images. IEEE Transactions on Geoscience and Remote Sensing 41: 2243-2253.

Morelli, S., S. Segoni, G. Manzo, L. Ermini, and F. Catani. 2012. Urban planning, flood risk and public policy: the case of the Arno River, Firenze, Italy. Applied Geography 34: 205-218. doi: http://dx.doi.org/10.1016/j.apgeog.2011.10.020.

Nolesini, T., F. Di Traglia, C. Del Ventisette, S. Moretti, and N. Casagli. 2013. Deformations and slope instability on Stromboli volcano: integration of GBInSAR data and analog modeling. Geomorphology 180: 242-254.

Nolesini, T., W. Frodella, S. Bianchini, and N. Casagli. 2016. Detecting Slope and Urban Potential Unstable Areas by Means of Multi-Platform Remote Sensing Techniques: The Volterra (Italy) Case Study. Remote Sensing 8(9): 746. doi:10.3390/rs8090746.

Oppikofer, T., M. Jaboyedoff, L. Blikra, M.H. Derron, and R. Metzer. 2009. Characterization and monitoring of the Åknes rockslide using terrestrial laser scanning. Natural Hazards and Earth System Sciences 9: 1003-1019.

Pappalardo, G., S. Mineo, S.P. Zampelli, A. Cubito, and D. Calcaterra. 2016. InfraRed thermography proposed for the estimation of the Cooling Rate Index in the remote survey of rock masses. International Journal of Rock Mechanics and Mining Sciences 83: 182-196.

Parker, A.L., J. Biggs, and Z. Lu. 2014. Investigationg long-term subsidence at Medicine Lake Volcano, CA, using multitemporal InSAR. Geophysical Journal International 199: 844-859.

Pazzi, V., S. Morelli, F. Fidolini, E. Krymi, N. Casagli, and R. Fanti. 2016. Testing costeffective methodologies for flood and seismic vulnerability assessment in communities of developing countries (Dajç, northern Albania). Geomatics, Natural Hazards and Risk 7(3): 971-999. doi: http://dx.doi.org/10.1080/ 19475705.2015.1004374.

Petley, D.N. 2012. The analysis of global landslide risk through the creation of a database of world-wide landslide fatalities. Geology 40(10): 927-930.

Petley, D.N., S.A. Dunning, N.J. Rosser, et al. 2005. The analysis of global landslide risk through the creation of a database of world-wide landslide fatalities. In Landslide risk management. London: Taylor \& Francis Group. ISBN 041538043X

Pieraccini, M., N. Casagli, G. Luzi, D. Tarchi, D. Mecatti, L. Noferini, and C. Atzeni. 2002. Landslide monitoring by ground-based radar interferometry: a field test in Valdarno (Italy). International Journal of Remote Sensing 24: 1385-1391.

Pieraccini, M., N. Casagli, G. Luzi, D. Tarchi, D. Mecatti, L. Noferini, and C. Atzeni. 2003. Landslide monitoring by ground-based radar interferometry: a field test in Valdarno (Italy). International Journal of Remote Sensing 24(6): 1385-1391.

Pratesi, F., T. Nolesini, S. Bianchini, D. Leva, L. Lombardi, R. Fanti, and N. Casagli. 2015. Early warning GBInSAR-based method for monitoring Volterra (Tuscany, Italy) city walls. IEEE Journal of Selected Topics In Applied Earth Observations And Remote Sensing 8(4): 1753-1762.

Raspini, F., Cigna, F., and Moretti, S. 2012. Multi-temporal mapping of land subsidence at basin scale exploiting Persistent Scatterer Interferometry: case study of Gioia Tauro plain (Italy). Journal of Maps 8(4):514-524.

Raspini, F., S. Moretti, and N. Casagli. 2013. Landslide mapping using SqueeSAR data: Giampilieri (Italy) case study. In Landslide science and practice, 147-154. Berlin Heidelberg: Springer.

Raspini, F., Loupasakis, C., Rozos, D., Adam, N., and Moretti, S. 2014. Ground subsidence phenomena in the Delta municipality region (Northern Greece): Geotechnical modeling and validation with Persistent Scatterer Interferometry. International Journal of Applied Earth Observation and Geoinformation, 28: 78-89.

Raspini, F., A. Ciampalini, S. Del Conte, L. Lombardi, M. Nocentini, G. Gigli, A. Ferretti, and N. Casagli. 2015a. Exploitation of amplitude and phase of satellite SAR images for landslide mapping: the case of Montescaglioso (South Italy). Remote Sensing 7(11): 14576-14596.

Raspini, F., A. Ciampalini, S. Bianchini, F. Bardi, F. Di Traglia, G. Basile, and S. Moretti. 2015b. Updated landslide inventory of the area between the Furiano and Rosmarino creeks (Sicily, Italy). Journal of Maps 12: 1-10.

Remondino, F., L. Barazzetti, F. Nex, M. Scaioni, and D. Sarazzi. 2011. Uav photogrammetry for mapping and $3 d$ modeling - current status and future perspectives-. International Archives of the Photogrammetry, Remote Sensing and Spatial Information Sciences, Volume XXXVIII-1/C22, 2011, ISPRS Zurich 2011 Workshop, 14-16 September 2011, Zurich, Switzerland. 
Righini, G., V. Pancioli, and N. Casagli. 2012. Updating landslide inventory maps using Persistent Scatterer Interferometry (PSI). International Journal of Remote Sensing 33(7): 2068-2096.

Rosen, P.A., S. Hensley, I.R. Joughin, F.K. Li, S.N. Madsen, E. Rodriguez, and R.M. Goldstein. 2000. Synthetic aperture radar interferometry. Proc. IEEE 88(3): 333-382.

Rosi, A., A. Agostini, V. Tofani, and N. Casagli. 2014. A procedure to map subsidence at the regional scale using the persistent scatterer interferometry (PSI) technique. Remote Sensing 2014(6): 10510-10522.

Rosi, A., V. Tofani, A. Agostini, L. Tanteri, C. Tacconi Stefanelli, F. Catani, and N. Casagli. 2016. Subsidence mapping at regional scale using persistent scatters interferometry (PSI): the case of Tuscany region (Italy). International journal of applied earth observation and geoinformation, vol. 52: 328-337.

Rosser, N.J., D.N. Petley, M. Lim, S.A. Dunning, and R.J. Allison. 2005. Terrestrial laser scanning for monitoring the process of hard rock coastal cliff erosion. Quarterly Journal of Engineering Geology and Hydrogeology 38: 363-375.

Rossi, G., M. Nocentini, L. Lombardi, P. Vannocci, L. Tanteri, G. Dotta, G. Bicocchi, G. Scaduto, T. Salvatici, V. Tofani, S. Moretti, and N. Casagli. 2016. Integration of multicopter drone measurements and ground-based data for landslide monitoring. Landslides and Engineered Slopes. Experience, Theory and Practice - Aversa et al. (Eds)@ 2016 Associazione Geotecnica Italiana, Rome, Italy.. ISBN 978-1-138-02988-0.

Rudolf, H., D. Leva, D. Tarchi, and A.J. Sieber. 1999. A mobile and versatile SAR system. Proceedings IGARSS 1: 592-594.

Scaioni, M., L. Longoni, V. Melillo, and M. Papini. 2014. Remote sensing for landslide investigations: an overview of recent achievements and perspectives. Remote Sensing 6(10): 9600-9652.

Scaioni, M., T. Feng, P. Lu, G. Qiao, X. Tong, R. Li, L. Barazzetti, M. Previtali, and R. Roncella. 2015. Close-range photogrammetric techniques for deformation measurement: applications to landslides. In Modern technologies for landslide monitoring and prediction, 13-41. Berlin Heidelberg: Springer.

Severin, J., E. Eberhardt, L. Leoni, and S. Fortin. 2014. Development and application of a pseudo-3D pit slope displacement map derived from ground-based radar. Engineering Geology 181: 202-211.

Singhroy, V. 1995. SAR integrated techniques for geohazard assessment. Advances in Space Research 15: 67-78.

Singhroy, V., K.E. Mattar, and A.L. Gray. 1998. Landslide characterisation in Canada using interferometric SAR and combined SAR and TM images. Advances in Space Research 21(3): 465-476.

Slob, S., H.R.G.K. Hack, and K. Turner. 2002. Approach to automate discontinuity measurements of rock faces using laser scanning techniques. In Proceedings of ISRM EUROCK 2002: Funchal, Portugal, 25-28 November 2002, ed. C. Dinid da Gama and L Riberia e Sousa, 87-94. Lisboa: Sociedade Portuguesa de Geotecnia.

Slob, S., H.R.G.K. Hack, Q. Feng, K. Röshoff, and A.K. Turner. 2007. Fracture mapping using 3D laser scanning techniques. In Proceedings of the 11th Congress of the International Society for Rock Mechanics, Lisbon, Portugal, vol. 1, 299-302.

Sousa, J.J., A.M. Ruiz, R.F. Hanssen, L. Bastos, A.J. Gil, J. Galindo-Zaldívar, and C. Sanz de Galdeano. 2010. PS-InSAR processing methodologies in the detection of field surface deformation - Study of the Granada basin (Central Betic Cordilleras, southern Spain). Journal of Geodynamics 49: 181-189.

Spampinato, L., S. Calvari, C. Oppenheimer, and E. Boschi. 2011. Volcano surveillance using infrared cameras. Earth-Science Reviews 106: 63-91.

Squarzoni, C., A. Galgaro, G. Teza, C.A.T. Acosta, M.A. Pernito, and N. Bucceri. 2008. Terrestrial laser scanner and infrared thermography in rock fall prone slope analysis. Geophysical Research Abstracts 10, EGU2008-A-09254, EGU General Assembly 2008.

Stavroulaki, M.E., B. Riveiro, G.A. Drosopoulos, M. Solla, P. Koutsianitis, and G.E. Stavroulakis. 2016. Modelling and strength evaluation of masonry bridges using terrestrial photogrammetry and finite elements.. Advances in Engineering Software.

Strozzi, T., U. Wegmuller, H.R. Keusen, K. Graf, and A. Wiesmann. 2006. Analysis of the terrain displacement along a funicular by SAR interferometry. IEEE Transactions on Geoscience and Remote Sensing 3: 15-18.

Sturzenegger, M., and D. Stead. 2009. Quantifying discontinuity orientation and persistence on high mountain rock slopes and large landslides using terrestrial remote sensing techniques. Natural Hazards and Earth System Sciences 9: 267-287.

Tapete, D., N. Casagli, G. Luzi, R. Fanti, G. Gigli, and D. Leva. 2013. Integrating radar and laser-based remote sensing techniques for monitoring structural deformation of archaeological monuments. Journal of Archaeological Science 40(1): 176-189.

Tapete, D., S. Morelli, R. Fanti, and N. Casagli. 2015. Localising deformation along the elevation of linear structures: an experiment with space-borne InSAR and
RTK GPS on the Roman Aqueducts in Rome, Italy. Applied Geography 58: 6583. doi: http://dx.doi.org/10.1016/j.apgeog.2015.01.009.

Tarchi, D., E. Ohlmer, and A.J. Sieber. 1997. Monitoring of structural changes by radar interferometry. Research in Nondestructive Evaluation 9: 213-225.

Tarchi, D., N. Casagli, R. Fanti, D. Leva, G. Luzi, A. Pasuto, M. Pieraccini, and S. Silvano. 2003. Landslide monitoring by using ground-based SAR interferometry: an example of application to the Tessina landslide in Italy. Engineering Geology 1(68): 15-30.

Teza, G., C. Atzeni, M. Balzani, A. Galgaro, G. Galvani, R. Genevois, G. Luzi, D. Mecatti, L. Noferini, M. Pieraccini, S. Silvano, F. Uccelli, and N. Zaltron. 2008. Groundbased monitoring of high-risk landslides through joint use of laser scanner and interferometric radar. International Journal of Remote Sensing 29(16): 4735-4756.

Teza, G., G. Marcato, E. Castelli, and A. Galgaro. 2012. IRTROCK: a matlab toolbox for contactless recognition of surface and shallow weakness traces of a rock mass by infrared thermography. Computers \& Geosciences 45: 109-118.

Teza, G., G. Marcato, A. Pasuto, and A. Galgaro. 2015. Integration of laser scanning and thermal imaging in monitoring optimization and assessment of rockfall hazard: a case history in the Carnic Alps (Northeastern Italy). Natural Hazards 76(3): 1535-1549.

Tofani, V., S. Segoni, A. Agostini, F. Catani, and N. Casagli. 2013a. Technical note: use of remote sensing for landslide studies in Europe. Natural Hazards and Earth System Sciences 13(2): 299-309.

Tofani, V., F. Raspini, F. Catani, and N. Casagli. 2013b. Persistent Scatterer Interferometry (PSI) technique for landslide characterization and monitoring. Remote Sensing 5(3): 1045-1065.

Turner, A.K., J. Kemeny, S. Slob, and H.R.G.K. Hack. 2006. Evaluation and management of unstable rock slopes by 3-D laser scanning. IAEG 404: 1-11.

Van Westen, C.J., E. Castellanos, and S.L. Kuriakose. 2008. Spatial data for landslide susceptibility, hazard, and vulnerability assessment: an overview. Engineering Geology 102: 112-131.

Vilardo, G., R. Isaia, G. Ventura, P. De Martino, and C. Terranova. 2010. InSAR permanent scatterer analysis reveals fault re-activation during inflation and deflation episodes at Campi Flegrei caldera. Remote Sensing of Environment 114: 2373-2383.

Voegtle, T., I. Schwab, and T. Landes. 2008. Influences of different materials on the measurements of a terrestrial laser scanner (TLS). In Proc. of the XXI Congress, The International Society for Photogrammetry and Remote Sensing, ISPRS2008, vol. 37, 1061-1066.

Werner, C., U. Wegmuller, T. Strozzi, and A. Wiesmann. 2003. Interferometric point target analysis for deformation mapping. In Geoscience and Remote Sensing Symposium (IGARSS), 2003 IEEE International, vol. 7, 4362-4364.

Westoby, M.J., J. Brasington, N.F. Glasser, M.J. Hambrey, and J.M. Reynolds. 2012. 'Structure-from-Motion'photogrammetry: a low-cost, effective tool for geoscience applications. Geomorphology 179: 300-314.

Wolter, A., D. Stead, and J.J. Clague. 2014. A morphologic characterisation of the 1963 Vajont Slide, Italy, using long-range terrestrial photogrammetry. Geomorphology 206: 147-164.

WPMLI (International Geotechnical Societies = UNESCO Working Party on World Landslide Inventory). 1993. Multilingual landslide glossary. BiTech Publishers Ltd.

Wu, J.H., H.M. Lin, D.H. Lee, and S.C. Fang. 2005. Integrity assessment of rock mass behind the shotcreted slope using thermography. Engineering Geology 80: 164.

Zhang, Z., S. Zheng, and Z. Zhan. 2004. Digital terrestrial photogrammetry with photo total station, 232-236. Istanbul, Turkey: International Archives of Photogrammetry and Remote Sensing.

\section{Submit your manuscript to a SpringerOpen ${ }^{\circ}$ journal and benefit from:}

- Convenient online submission

- Rigorous peer review

- Immediate publication on acceptance

- Open access: articles freely available online

- High visibility within the field

- Retaining the copyright to your article

Submit your next manuscript at $>$ springeropen.com 